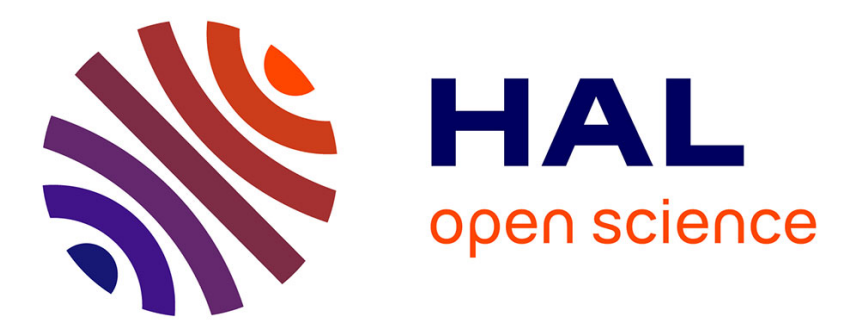

\title{
Decision-based territorial life cycle assessment for the management of cement concrete demolition waste
}

\author{
Marjan Mousavi, Anne Ventura, Nicolas Antheaume
}

\section{To cite this version:}

Marjan Mousavi, Anne Ventura, Nicolas Antheaume. Decision-based territorial life cycle assessment for the management of cement concrete demolition waste. Waste Management and Research, 2020, pp.1405-1419. 10.1177/0734242X20965676 . hal-03472495

\section{HAL Id: hal-03472495 \\ https://hal.science/hal-03472495}

Submitted on 9 Dec 2021

HAL is a multi-disciplinary open access archive for the deposit and dissemination of scientific research documents, whether they are published or not. The documents may come from teaching and research institutions in France or abroad, or from public or private research centers.
L'archive ouverte pluridisciplinaire HAL, est destinée au dépôt et à la diffusion de documents scientifiques de niveau recherche, publiés ou non, émanant des établissements d'enseignement et de recherche français ou étrangers, des laboratoires publics ou privés. 


\section{Decision-based territorial Life Cycle Assessment for the Management of Cement Concrete Demolition Waste}

Mousavi Marjan ${ }^{1,2}$, Ventura Anne*1,3,5, Antheaume Nicolas ${ }^{4,5}$

1. University of Nantes, GeM, Institut de Recherche en Génie civil et Mécanique - CNRS UMR 6183 - Chaire Génie Civil Eco-construction, 44606 Saint-Nazaire cedex, France

2. RISE Research Institutes of Sweden, Division of Built Environment, Department of Infrastructure and Concrete Constructions, Unit of Environmental Analysis and Constructions, Sweden

3. University Gustave Eiffel (IFSTTAR) MAST/GPEM, Campus of Nantes, 44344 Bouguenais cedex, France.

4. Laboratory of Economics and Management Nantes Atlantique (LEMNA), University of Nantes, 44322 Nantes, France

5. Institut de Recherche des Sciences et Techniques de la Ville (IRSTV), Ecole Centrale de Nantes, 44321 Nantes, France 


\begin{abstract}
Existing territorial LCAs consider all activities in a given geographical area, defined as the foreground system, but cannot lead to operational decision. In product scale LCA, the foreground system is defined as the part of the system directly controlled by an actor and is thus more adapted to compare possible scenarios within a decision perimeter. The present paper uses that concept applied to a geographical area. The developed method consists of 5 steps: (i) definition of the foreground MFA/LCA system corresponding to the decision perimeter, (ii) territorial MFA, (iii) geo-location of activities and downscaling of territorial flows to individual activities, (iv) calculation of local transport distances and (v) calculation of LCA impact indicators. The case study concerns the management of primary and secondary resources of Basic Quality aggregates (BQA) in the Loire Atlantique department (France) in 2012. Our results show that the amount of Recycled Cement Concrete (RCC) is only 7\% of total consumed BQA, although $90 \%$ of Cement Concrete Demolition Waste (CCDW) is recycled. The environmental impacts are importantly related to off-site activities. Local impacts are mainly driven by the transport of aggregates. For land planning, a concentration of fewer recycling facilities with high authorised production capacities in main cities, close to where CCDW is mainly produced, would divide transport needs by 2 and thus considerably reduce environmental impacts.
\end{abstract}

Keywords: urban metabolism, material flow analysis, geographical downscale, recycling 


\section{INTRODUCTION}

Urban Metabolism (UM) is a general framework which aims at analysing the interactions between human societies and nature, in a known geographical area, often a city and its suburbs, based on the observation and analysis of stocks and flows (Kennedy et al., 2007). Since the stocks and flows considered are mainly materials and energy, territorial Material Flow Analysis (MFA) is one of the most widely applied method in UM studies. $\mathrm{UM}$ is generally conducted in order to provide insights for more sustainable territories. However, previous research pointed out that indirect flows were not considered or poorly estimated in territorial MFAs (Barles, 2010). These so-called indirect or hidden flows, are those generated by activities inside the observed territory, but occurring outside this territory. More explicitly, they are upstream flows necessary for a production or a consumption (i.e. energy, products, nutrients, etc.), downstream flows necessary from the result of a production or a consumption (i.e. energy for transport, waste treatment, etc.), as well as flows from and to nature that are themselves generated by the corresponding activities. Later, the literature reviews of UM methods by Loiseau et al. (2012) and Pincetl et al. (2012) both suggested an expanded UM framework in order to integrate a life cycle perspective, and a general framework was set (Chester et al., 2012; Loiseau et al., 2013), marking the beginning to what was later called territorial LCA (Loiseau et al., 2018), to be distinguished from product LCAs that are "classical" LCAs. Several case studies followed.

The two first applied territorial LCAs were the comparison of several cities (Goldstein et al., 2013) and the study of a rural territory (Loiseau et al., 2014). A comparison of their models is provided in Table 1. Their results showed a comparison of tonnes of $\mathrm{CO}_{2}$ equivalent with per capita Gross Domestic Product (GDP) between several cities detailing the contributions of considered activities (Goldstein et al., 2013). The research also included several impact indicators detailing the contributions of considered activities, completed by an analysis of contributions between on-site and off-site as well as between consumption and production (Loiseau et al., 2014).

Although these studies provide very interesting insights about geographical areas, such as the main activities causing environmental impacts and the dependency of the studied area on activities occurring off-site, they cannot lead to operational decision making. Indeed, fundamentally, a decision-maker's role consists in 
addressing problems with effective actions that can be controlled, knowing the consequences of each possible action (Senga Kiessé et al., 2017). In classical product LCA, the foreground system is defined as "the part of the system that is directly controlled by a given actor" (Frischknecht, 1998) and is thus adapted to compare possible scenarios within the decision perimeter of a given actor. In previous territorial LCA studies, the foreground system has been defined as the territory (see Table 1), which cannot be related to a given actor.

Table 1. Comparison of models used by the two first territorial LCA applied studies - *Gross Domestic Product; MFA: Material Flow Analysis

\begin{tabular}{|l|l|l|}
\hline Reference & \multicolumn{1}{|c|}{ (Goldstein et al., 2013) } & \multicolumn{1}{c|}{ (Loiseau et al., 2014) } \\
\hline Reference flow & Geographical area: city & Geographical area: rural area \\
\hline Functional unit & Capita GDP* & $\begin{array}{l}\text { Based on land use functions (environmental, } \\
\text { societal and economic) with an initial land planning } \\
\text { scenario determined from the analysis of territory }\end{array}$ \\
\hline $\begin{array}{l}\text { Foreground } \\
\text { system }\end{array}$ & The geographical area (on-site) & The geographical area (on-site) \\
\hline $\begin{array}{l}\text { Considered } \\
\text { activities in } \\
\text { territory }\end{array}$ & $\begin{array}{l}\text { Consumption: food for residents, construction } \\
\text { materials for growth/maintenance of building stock } \\
\text { and infrastructure, energy for transport, buildings } \\
\text { and industry, and other materials commonly } \\
\text { consumed en masse }\end{array}$ & $\begin{array}{l}\text { Consumption for residents and tourists (food, } \\
\text { housing, transports, waste and wastewater) } \\
\text { On-site production: agriculture, fishing, quarries, } \\
\text { manufacturing activities, construction, energy, waste } \\
\text { elimination, storage, transport, services and tertiary } \\
\text { activities }\end{array}$ \\
\hline $\begin{array}{l}\text { Background } \\
\text { system }\end{array}$ & $\begin{array}{l}\text { Upstream and downstream systems } \\
\text { corresponding to flows of the foreground system } \\
\text { (off-site) }\end{array}$ & $\begin{array}{l}\text { Upstream systems corresponding to flows of the } \\
\text { foreground system (off-site) }\end{array}$ \\
\hline $\begin{array}{l}\text { Data source for } \\
\text { flows }\end{array}$ & \begin{tabular}{l} 
Previous MFA studies, economic databases \\
\hline
\end{tabular} & Economic databases, local surveys \\
\hline
\end{tabular}

In order for territorial LCA to aim at making decisions, then the foreground system should be different from the on-site area, as defined by its geographical boundaries (Ventura, 2020), as shown in Fig. 1. 


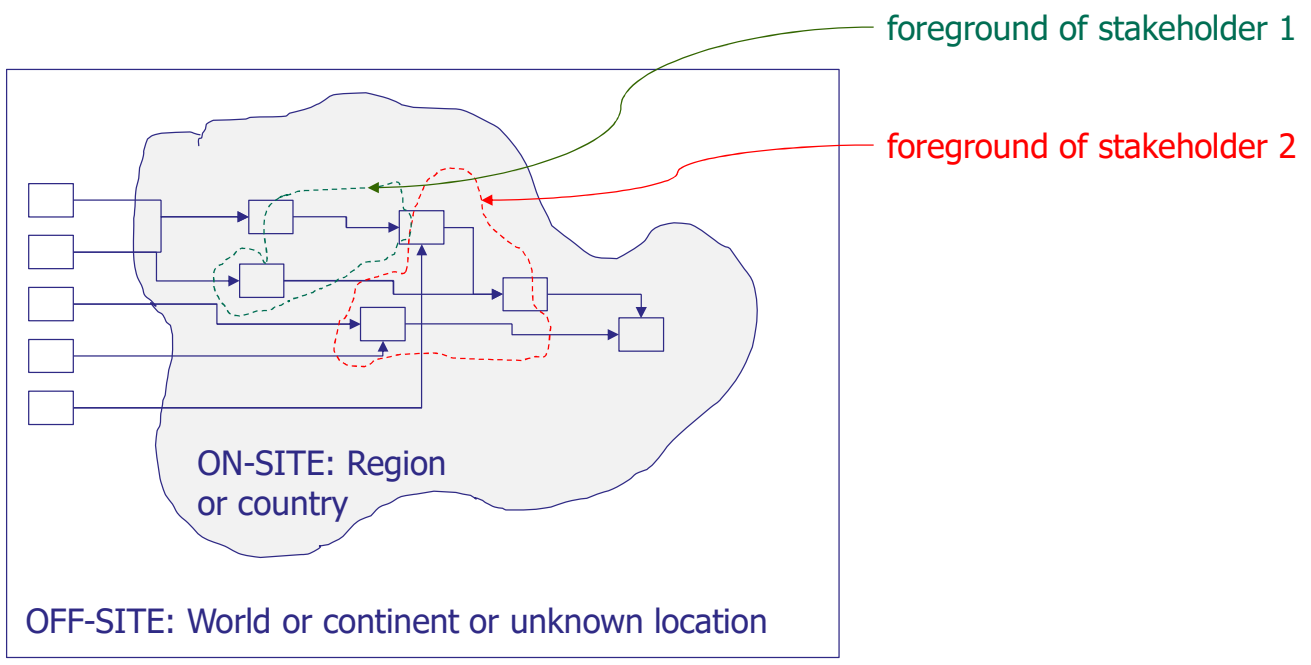

Fig. 1. Conceptual distinction between LCA foreground system and MFA geographical boundaries

Such a distinction allows focusing on a set of activities within a given action perimeter and not describing all the activities of a geographical area. Thus, in that case, territorial LCA is not comprehensive in terms of activities. It focuses on a system and on scenarios within a decision perimeter. This was suggested previously (Bidstrup et al., 2015) for the study of land planning scenarios, in a five steps methodology. The first step consists in identifying planning variables (Bidstrup et al., 2015). The second step is to develop the LCA model, inside which "planning variables are formulated as foreground parameters in the system". The third step consists in formulating planning scenarios and defining a baseline scenario (Bidstrup et al., 2015). The fourth step consists in calculating an analysing environmental impacts, and the fifth and last step consists in formulating planning recommendations (Bidstrup et al., 2015).

In this research paper, the objective is to conduct a territorial LCA for supporting decision in the concrete waste management system. In France, the planning of waste management is delegated to regional authorities (JORF, 2015a) through a "Plan Régional de Prévention et de Gestion des Déchets" (PRPGD). The first chapter of the PRGPD must integrate a diagnosis of resources and energy, as well as input and output flows at the regional scale. It should map the main waste producing activities and identify synergies which enable waste recovery. It should list existing initiatives which promote the circular economy as well as waste prevention, reduction and recovery (JORF, 2015a). The second chapter of the PRGPD must provide prospective scenarios for the next 6 to 
12 years and quantify their employment potentials (JORF, 2015a). The third chapter must describe a regional governance system including the waste management stakeholders in the region (JORF, 2015a). The fourth chapter sets objectives for an efficient waste and resource management system. The fifth and last chapter defines actions conducted in order to promote the circular economy (JORF, 2015a).

According to the concepts presented in Fig. 1, the foreground system represents the decision perimeter of French regional authorities. The present study particularly contributes to the diagnosis of waste and resource as required by the first PRGPD chapter, by calculating environmental impacts of the current cement concrete waste management system. This article focuses on steps 1 and 2 in the conceptual framework defined by Bidstrup et al. (2015).

According to Pepe (2015), cement concrete demolition waste (CCDW) represents about one third of total Construction and Demolition Waste (C\&DW), excluding excavated soil. Indeed, the high compressive strength of concrete, its high durability, low maintenance cost and resistance to different weather conditions as well as its low purchase price compared to other construction materials make it one of the most widely used construction materials (Behera et al., 2014). In the same time, 20 billion tonnes of natural aggregate are consumed every year on a global scale and an annual growth rate of $4.7 \%$ is expected in the coming years (Pacheco-Torgal et al., 2013). This leads to the consumption of non-renewable raw materials, energy consumption and to a reduction of biodiversity at extraction sites (Pacheco-Torgal et al., 2013). Hence, construction materials must be produced and used according to sustainable development principles (Blengini and Garbarino, 2010) in order to minimize economic, energy and environmental burdens caused by the construction industry. According to current practice, CCDW are recycled into Recycled Cement Concrete (RCC). RCC serve as Basic Quality Aggregates (BQA), which are the lowest quality of aggregates used for foundations (roads, buildings and railways, tracks) and trenches (Thorn and Brown, 1989). BQA are also extracted from natural resource in quarries (designed as A1 in this article).

The present study thus considers the waste and resource management system of BQA. It first presents the method as well as its application to the case study of the Loire Atlantique department located in the Pays de la Loire region (France). Then it presents and discusses the impact assessment results. 


\section{METHOD}

The developed method consists in 5 steps. First, the MFA/LCA foreground system is defined, and in a second step, an MFA of that system is conducted at the studied geographical scale. In a third step, the activities of the system in the studied geographical area, are geo-localized and the values of reference flows are determined for each single activity site using a downscale method. Then, as a fourth step, transport distances associated to the reference flows are calculated. Finally, other flows related to reference flows (other intermediary flows, and elementary flows) for both foreground and background systems, are calculated to obtain LCA impact indicators.

\subsection{Definition of the MFA/LCA system}

The system is depicted in Fig. 2 (the values of stocks and flows will be detailed in the next section). The waste and resource management system of BQA is the system producing and provisioning BQA for construction purposes. Two products, RCC and A1, compete for the same usage, and, for constant BQA demand, an increase of the use of RCC results is a decrease in the use of A1. Thus, the system should account for productions and provisioning of both resources, because of this causal relationship.

RCC is produced from recycling facilities that transform CCDW into RCC using crushers and grinders. The system thus includes the total amounts of CCDW transported to recycling facilities, the total amounts of RCC produced from these facilities as well as their transport to the construction site for which they are provisioned. Demolition activities are not considered as a part of the system as we consider that they belong to the buildings' life cycle. In addition, there is no observed correlation between the amount of cement concrete used for building construction and CCDW production. Indeed, buildings can be composed of other materials than concrete, and their service life is long and uncertain. At the end of their service life, buildings are not always demolished (they can be renewed or refurbished), and demolition can also be provoked by urban planning policies (Augiseau and Barles, 2017). Thus, the model only accounts for the available CCDW at a given time, without modelling any physical relationship with the building construction activity.

Quarries produce three qualities of aggregates: 
- high quality aggregates (designated as A3 in this article) used with hydraulic or bituminous binders for high grade applications (cement concrete and asphalt respectively)

- medium quality aggregates (designated as A2 in this article) used for road base layers

- and basic quality aggregates (designated as A1 in this article) used for foundations (roads, buildings and railways, tracks) and trenches.

Basic and medium quality aggregates, A1 and A2, are co-products of the quarry process: they are jointly produced with high quality aggregates A3 that are the quarries' main products. Thus, the system should account for total production of $\mathrm{A} 1$ as an output related to the total amount of A3 produced. The activities which are dedicated to A2 and A3 production in quarries should not be included based on an allocation method. Finally, the system should account for the transport of A1 from the quarry to the construction site for which they are provisioned.

Because a part of the CCDW are also sent to backfilling or inert landfill facilities, the system should also include their transport and waste treatment process. Backfilling is legally considered as a recovery process (JORF, 2015b), whereas inert landfilling is legally considered as a waste elimination process. However, both activities are identical processes and thus have identical environmental impacts. Consequently, both activities are considered as a single and identical process in the system model, called inert landfill.

Finally, because both BQA resources are constraints, i.e. they are not produced according to a market demand, but according to demolition activities for RCC and to A3 production for A1, stocks have to be considered, as their production may exceed the market demand. According to experts opinions, recycling facilities can temporarily stock CCDW, and produce RCC on demand. However, durable storage of CCDW is not allowed by law, and it was thus assumed that when the amount of CCDW exceeds the BQA market needs, it is sent for landfilling. Thus, the system model does not require a stock of CCDW. 


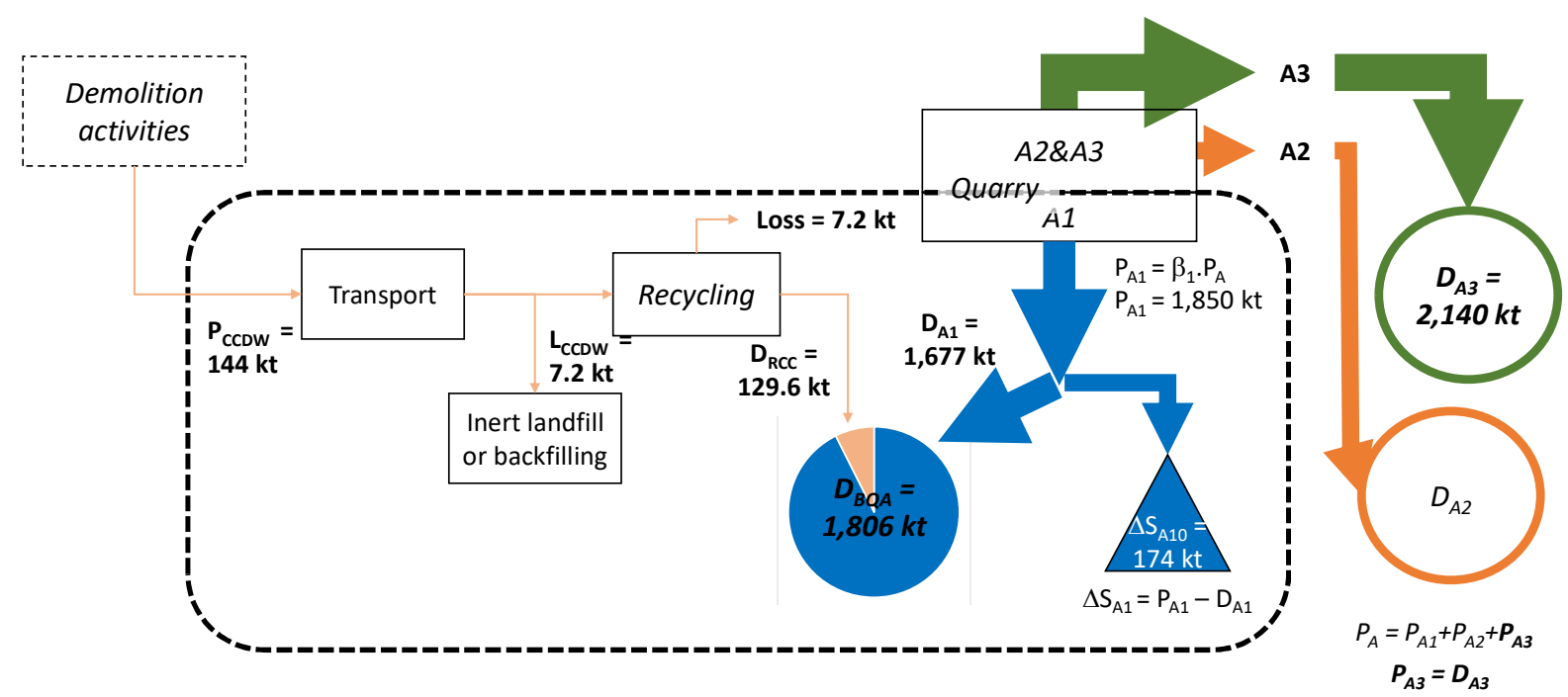

Fig. 2. System model of the waste and resource management of BQA - indicated masses (ktonnes) concern the Loire Atlantique department in 2012.

Legend
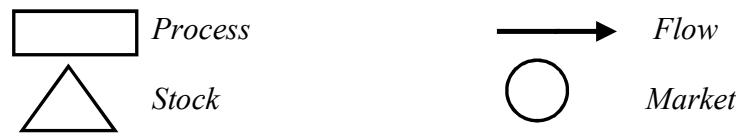

\begin{tabular}{|c|c|c|}
\hline$D_{B Q A}$ & ktonne.year ${ }^{-1}$ & Annual market demand for $B Q A$ \\
\hline$P_{A 3}=D_{A 3}$ & ktonne.year ${ }^{-1}$ & Annual market demand for A3 (production adjusted to demand) \\
\hline$D_{A 2}$ & ktonne.year-1 & Annual market demand for $A 2$ \\
\hline$D_{A 1}$ & ktonne.year ${ }^{-1}$ & Annual market demand for Al \\
\hline$D_{R C C}$ & ktonne.year-1 & Annual market demand for $R C C$ \\
\hline$P_{A l}$ & ktonne.year-1 & Annual production of A1 \\
\hline$P_{C C D W}$ & ktonne.year-1 & Annual production of $C C D W$ \\
\hline$L_{C C D W}$ & ktonne.year-1 & Annual landfill and backfilling of $C C D W$ \\
\hline$\Delta S_{A 1}$ & ktonne.year-1 & Addition to stock of Al aggregates \\
\hline$\beta_{1}$ & n.u. & Mass ratio of A1 to total production of the quarry \\
\hline
\end{tabular}

\subsection{MFA of system at departmental scale}

\subsubsection{Stocks and flows of natural aggregates}

The production of A3 is not constrained, i.e. production is adjusted to demand, thus it is assumed $\mathrm{P}_{\mathrm{A} 3}=\mathrm{D}_{\mathrm{A} 3}$. The market demand for A3 is calculated from markets of cement and bituminous concrete.

$$
D_{A 3}=P_{A 3}=D_{A 3 C C}+D_{A 3 B C}
$$

Equation 1

Where $D_{A 3}$ and $P_{A 3}$ are the total demand and total production respectively, assuming production is adjusted to demand, of the studied geographical area for $A 3$ (tonne), $D_{A 3 C C}$ and $D_{A 3 B C}$ are the total demands for $A 3$ (tonne) in the markets of cement concrete and bituminous concrete respectively in the same year. 
$\mathrm{D}_{\mathrm{A} 3 \mathrm{CC}}$ can be estimated from the total demand for cement concrete (in cubic meters) in the studied geographical area using the following equation:

$$
D_{A 3 C C}=M_{A 3 C C} \cdot D_{C C} \quad \text { Equation } 2
$$

Where $M_{A 3 c C}$ is the mass intensity of High Quality Aggregates in Cement Concrete (tonne aggregate. $m^{-3}$ cement concrete) and $D_{C C}$ is the annual total amount of market demand for cement concrete $\left(\mathrm{m}^{3}\right)$ consumed in the studied geographical area.

According to the literature, the mass intensity $\mathrm{M}_{\mathrm{A} 3 \mathrm{CC}}$ is assumed 1.207 tonne. $\mathrm{m}^{-3}$ of cement concrete, corresponding to a cement concrete with a $40 \mathrm{MPa}$ compressive strength (Etxeberria et al., 2007).

$\mathrm{D}_{\mathrm{A} 3 \mathrm{BC}}$ can be estimated from the total demand for bituminous concrete in the studied geographical area using the following equation:

$$
D_{A 3 B C}=M_{A 3 B C} \cdot D_{B C} \quad \text { Equation } 3
$$

Where $M_{A 3 B C}$ is the mass intensity of High Quality Aggregates (tonne aggregate.tonne ${ }^{-1}$ asphalt) and $D_{B C}$ is the annual market demand for bituminous concrete (tonne) consumed in the studied geographical area.

$M_{A 3 B C}$ is assumed equal to 0.95 (Ventura et al., 2008).

Productions of $\mathrm{A} 1$ and $\mathrm{A} 2\left(\mathrm{P}_{\mathrm{A} 1}\right.$ and $\mathrm{P}_{\mathrm{A} 2}$, see Fig. 2) are derived from $\mathrm{D}_{\mathrm{A} 3}$ (obtained from Equation 1) using mass proportions of A1, A2 and A3 productions symbolized by $\beta_{1}, \beta_{2}$ and $\beta_{3}$ respectively and defined in Equation 4 .

$$
\begin{aligned}
& P_{A 1}=\beta_{1} \cdot P_{T} \\
& P_{A 2}=\beta_{2} \cdot P_{T} \\
& P_{A 3}=\beta_{3} \cdot P_{T}
\end{aligned}
$$

Equation 4

Where $P_{T}$ is the total production of aggregates in the quarry in the studied geographical area, $P_{A 1}$ is the total production of $A 1$ (tonne) in the quarry in the studied geographical area, $P_{A 2}$ is the total production of $A 2$ (tonne) in the quarry in the studied geographical area and $P_{A 3}$ is the total production of $A 3$ (tonne), $\beta_{1}, \beta_{2}$ and $\beta_{3}$ are the average mass ratios of $A 1, A 2$ and $A 3$ produced in the quarries respectively $\left(\beta_{1}+\beta_{2}+\beta_{3}=1\right)$.

Productions of A1 and A2 can be calculated from the one of A3, as detailed in Equation 5.

$$
\begin{aligned}
& P_{A 1}=\frac{\beta_{1}}{\beta_{3}} \cdot P_{A 3} \\
& P_{A 2}=\frac{\beta_{2}}{\beta_{3}} \cdot P_{A 3}
\end{aligned}
$$

Equation 5

Demand for A1 is calculated from total demand in aggregates, and demands for A3 and A2.

$$
D_{A 1}=D_{A}-D_{A 3}-D_{A 2}
$$


Where $D_{A}$ is the total annual demand for aggregates in the studied geographical area, $D_{A 1}$ is the total demand for $B Q A$ in the studied geographical area, $D_{A 2}$ is the total demand for medium quality aggregates in the studied geographical area, and $\gamma_{2}$ is average mass ratio of market demand for $A 2$ to market demand for A3.

\subsubsection{Stocks and flows of Cement Concrete Demolition Waste}

Amounts of CCDW sent to landfills can be expressed by Equation 7:

$$
L_{C C D W}=P_{C C D W}-D_{R C C}
$$

Equation 7

Where $L_{C C D W}$ is the total annual mass of CCDW (tonne) that is disposed into the landfill, PCCDW is the total mass of CCDW (tonne) produced in the same year and $D_{R C C}$ is the market demand for RCC (tonne) in the same year.

\subsection{Downscaling method}

The downscaling method aims at estimating the amounts of CCDW produced in each demolition site, the total BQA consumed in each construction site, as well as the BQA production for each facility. After geo-location of activities, an algorithm is used to partition total flows at departmental scale between activities and calculate the corresponding transport distances.

\subsubsection{Geo-location of construction/demolition sites and facilities}

It first requires to build up a geo-spatial database of BQA providers, with all the quarries, recycling facilities and landfill facilities, with their production capacities in the studied geographical area. The way to build up this database can vary according to the existing local information. It is fully described in the following case study. The X-Y coordinates of the cities in which facilities are located have been identified from the DoGeocodeur website (DoGeocodeur, n.d.).

However, the geo-location of demolition and construction sites, i.e. CCDW producers and BQA consumers/buyers, cannot be known. It is thus assumed that the territory can be divided into several geographical segments, and that the centre of gravity of the population of each segment is a proxy for local demolition and construction sites. As a result, the number of buyers will equal the numbers of geographical segments that are considered. Equation 8 and Equation 9 give $X_{m}$ and $Y_{m}$ coordinates of construction/demolition site $\mathrm{m}^{\text {th }}$ on the map in geographical segment $\mathrm{m}^{\text {th }}$. 


$$
X_{m}=\frac{\sum x_{j, m} * \text { Pop }_{j, m}}{\sum \text { Pop }_{j, m}}
$$

Where $x_{j, m}$ is the position of unitary sector $j^{\text {th }}$ in geographical segment $m^{\text {th }}$ from $X$ axis and Pop $p_{j, m}$ is the population of the unitary sector $j^{\text {th }}$ in geographical segment $m^{\text {th }} . m$ is the numbers of the geographical segments on the given map.

$$
Y_{m}=\frac{\sum y_{j, m} * P_{o p} p_{j, m}}{\sum P o p_{j, m}}
$$

Equation 9

Where $y_{j, m}$ is the position of unitary sector $j^{\text {th }}$ in geographical segment $m^{\text {th }}$ from $Y$ axis and Pop $p_{j, m}$ is the population of the unitary sector $j^{\text {th }}$ in geographical segment $m^{\text {th }} . m$ is the numbers of the geographical segments on the given map.

\subsubsection{BQA demand and CCDW production in a geographical segment}

According to (Sandberg et al., 2016) the demand for construction materials is usually proportional to the population at country scale. Thus, it is assumed that this is also valid at the level of a geographical segmental. The demand of a buyer in a geographical segment for BQAs (either A1 or RCC) can be estimated from Equation 10.

$$
D_{B Q A_{m}}=\frac{P o p_{m}}{P o p} * D_{B Q A}
$$

Equation 10

Where $D_{B Q A_{m}}$ is the annual amount of $B Q A$ s demand (tonnes) in geographical segment $m^{\text {th }}$.

With the same assumption, production of CCDW can be calculated from:

$$
P_{C C D W}=\frac{P o p_{m}}{P o p} * P_{C C D W}
$$

Where $P_{C C D W}{ }_{m}$ is the annual production of CCDW (tonnes) in geographical segment $m^{\text {th }}$.

Consequently, the outputs of the algorithm are the following: (a) demands of a buyer for A1 (or RCC) from different quarries $D_{A 1_{m, Q i}}$, (or $D_{R C C_{m, R e c i}}$ ); and (b) distances travelled between the buyers of A1 (or RCC) and different quarries $d_{m, Q i}$ (or recycling facilities $d_{m, R e c i}$ ).

Total tonne.kilometer for A1 (or RCC) from producer to market are calculated from Equation 12. 


$$
T_{D_{B Q A}}=\sum_{i, m} D_{B Q A_{i, m}} * d_{i, m} * 2
$$

Equation 12

Where $T_{D B Q A}$ is the total tonne.kilometre resulting from the demand of $B Q A$ of buyers from different facilities in the studied geographical area, $D_{B Q A_{i, m}}$ is the demand of buyer of geographical segment $m$ for $B Q A$ from facility $i$ (tonne) and $d_{i, m}$ is the distance between the buyer of geographical segment $m$ and facility $i(\mathrm{~km}), m$ is the index designating the geographical segments, $i$ is the index designating the BQA production facility (either quarry or recycling facility). Coefficient 2 corresponds to the return trip (ecoinvent 3.3 cut-off database includes a part of $25 \%$ empty travels corresponding to return trips (Moreno Ruiz et al., 2016; Spielmann et al., 2007)).

Total tonne.kilometre for transport of CCDW from demolition site to recycling facilities are obtained from Equation 13.

$$
T_{R_{C C D W}}=\sum_{i=1 \text { to } R} R_{C C D W i, m} * d_{i, m} * 2
$$

Where $T_{R_{C C D W}}$ is the total tonne.kilometre resulting from the transportation of CCDW to recycling facilities in the studied geographical area, $R_{C C D W}$ i, is the amount of $C C D W$ produced in geographical segment $m$ and sent to the recycling facility $i$ (tonne), and $R$ is the number of recycling facilities in the geographical segment $m$.

The amount of unsold RCC is considered equal to the amount of CCDW sent to landfill $\mathrm{L}_{\mathrm{CCDW}}$ in Equation 7. Total tonne.kilometre for transport of CCDW from demolition site to landfill facilities are obtained from Equation 14.

$$
T_{L_{C C D W}}=\sum_{\mathrm{i}=1 \text { to } \mathrm{L}} L_{C C D W i, m} * d_{i, m} * 2
$$

Where $T_{L_{C C D W}}$ is the total tonne.kilometre resulting from the transportation of CCDW to landfill facilities in the studied geographical area, $L_{C C D W} i, m$ is the amount of $C C D W$ produced in geographical segment $m$ and sent to the landfill facility $L$ (tonne), $L$ is the number of landfill facilities.

\subsubsection{Downscaling algorithm}

The developed algorithm is detailed in the Supporting Information (Fig. S 1). Total demands are known and corresponds to DA1 and DRCC (see Fig. 2), total additions to stocks are known and correspond to $\triangle \mathrm{SA} 1$ and LCCDW (see Fig. 2). Assuming that the demand for RCC and A1 at the scale of the studied geographical area is valid in each geographical segment, the algorithm thus aims at calculating which providers have sold to which buyers, to obtain produced and stocked amounts of RCC and A1 in each facility. The choice of buyers between providers is done by increasing order of distance. Outputs of the algorithm are amounts sold and left material for each facility (quarries and recycling platforms) as well as transport distances for each type of resource (A1 and 
RCC). These outputs are used in the LCA model in order to calculate the environmental impacts of this reference scenario.

Consequently, the outputs of the algorithm are: demands of a buyer for A1 (or RCC) from different quarries $D_{A 1_{i, m}}\left(D_{R C C_{i, m}}\right)$, distances travelled between the buyers of A1 (or RCC) and different quarries $d_{A 1, m}$ (or recycling facilities $\left.d_{R C C, m}\right)$.

\subsection{LCA process models for activities}

LCA is used to assess the environmental impacts of the system described in Fig. 2. Flows represented in the MFA model are intermediate reference flows in the LCA model. The LCA model is developed using OpenLCA 1.10 and the ecoinvent cut-off 3.3 database with some adaptations of existing processes. This database was chosen because it provides all the process models needed alongside with detailed written justifications. This allows for the modifications of some process models when justified, i.e. for adaptation to a different country, or for a more detailed model (such as the one presented below for the quarry process).

\subsubsection{Quarry process}

The actual quarry process is a multi-output process, which produces three products with different mass ratios, while the quarry process in the ecoinvent database has one single product. The process called "gravel production, crushed $[\mathrm{CH}]$ " was chosen from the ecoinvent cut-off 3.3 and adapted to model a new quarry process reflecting the three treatment lines producing the three qualities of aggregates A1, A2 and A3.

The newly modelled quarry process is detailed in Fig. 3. Each treatment line contains crushing and gridding processes that produces different categories of natural aggregates (A1, A2 or A3). The rocks extracted from the ground are crushed in the first treatment line. Some parts of the crushed gravels due to their quality (more friable) cannot pass through the secondary treatment. They are kept as BQA natural aggregates (A1). The rest is sent to the second treatment line. The most friable parts of the aggregates are kept as medium quality natural aggregates (A2). They cannot pass through the third treatment line. The rest are sent to the third treatment line and crushed into different sizes to produce high quality natural aggregates (A3). 
The "gravel production, crushed $[\mathrm{CH}]$ " process was adapted to the French situation by considering the French electric mix. All its flows values were divided by three, corresponding to the three treatment lines, in order to model one single treatment line. Each treatment line producing A1, A2 and A3 was multiplied by factors F1, F2 and F3 respectively, corresponding to the partition of environmental impacts attributed to each quality of aggregates and calculated as indicated in Fig. 3. Only the part of quarry process corresponding to the production of A1 is included in the system as shown in Fig. 2.

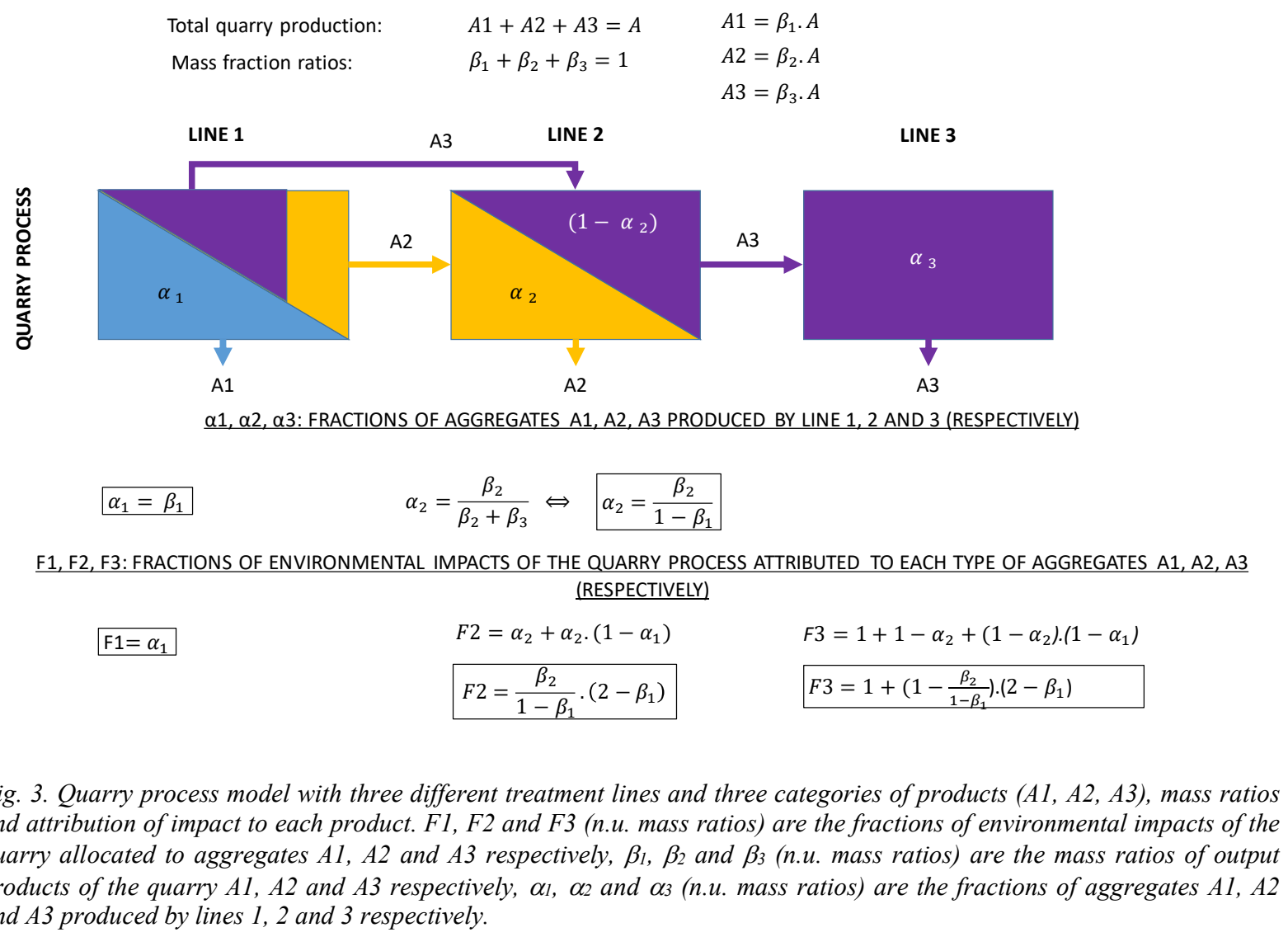

\subsubsection{Inert landfilling process}

The "treatment of waste concrete, inert material landfill $[\mathrm{CH}]$ " process in the ecoinvent cut-off v3.3 database was considered as an inert landfilling process of CCDW. Electricity production and heat and power cogeneration processes were adapted to the case of France. 


\subsubsection{Recycling process}

The recycling process of CCDW is similar to crushing of aggregates in the quarry, but with a single treatment line. Thus, it is equivalent to a single treatment line as described above for the quarry process, but without a partition ratio as it provides a single product RCC. For recycling facilities, the flow corresponding to the infrastructure is multiplied by an Infrastructure Factor (IF) representing the actual use of the infrastructure for the recycling production activity. Indeed, these facilities operate with a mobile crusher that is only used a few weeks per year. According to expert judgment, for a 20,000 tonnes annual production, a mobile crusher is required for 3 weeks ( 8 hours a day excluding weekends) that makes a 0,057 annual use ratio for 20,000 tonnes, and thus IF $=2.88 \times 10^{-6}$ for one tonne of produced RCC.

Three different types of recycling facilities are considered: (i) facilities dedicated to the recycling process, (ii) facilities that are jointly operated with a landfill facility, and (iii) facilities that are jointly operated with quarries. According to the type of recycling facility, different changes are made to adapt the process.

- Dedicated recycling facilities: the situation is the same as recycling facilities jointly operated with quarries. No infrastructure flows are considered except for the crusher.

- Recycling facility jointly operated with landfill: the recycling process is the same as the one defined for the dedicated recycling facilities. The infrastructure flow is considered as belonging to the landfill facility and no part of it is allocated to the recycling facility.

- Recycling facilities jointly operated with quarries: the infrastructure flow is considered as belonging to the quarry process and no part of it is allocated to the recycling facility, except for the crusher. Indeed, based on expert opinions, quarries do not use their own equipment for the production of recycled materials, but use additional mobile crushers.

\subsubsection{Stocks of natural aggregates}

Stocks in of A1 (see Fig. 2) are assumed to be similar to the process "process-specific burdens production, inert material landfill $[\mathrm{CH}]$ " in the ecoinvent cut-off v3.3 database, but without transportation and infrastructure flows. Indeed, these stocks are located in the quarries, thus not requiring transport nor specific additional infrastructures. Electricity production as well as heat and power co-generation processes were adapted to the case of France. 


\subsubsection{Transport process}

A process "transport, freight, lorry $>32$ metric ton, 2012 [FR]" has been modelled according to the composition of trucks for road transport in 2012 in France (CNR, 2013) presented in Table S 3 (see Supporting Information). This composition was used to model the transportation process in the system model for the studied geographical area, with EURO 0,1 and 2 considered as EURO 3 in the model. Knowing the positions of providers and construction/demolition sites (see previous section), allows calculating the distances between each construction/demolition site and each provider (see Table S 5 in Supporting Information).

\subsubsection{Impact assessment}

The International Reference Life Cycle Data System (ILCD) (Joint Research Centre, 2011) is used as the main life cycle impact assessment (LCIA) method (named ILCD 2011, midpoint [v1.0.10, August 2016]) in the OpenLCA 1.7.4 software. Impacts have also been normalized using Normalization factors JRC EU 27, 2010 available in the OpenLCA 1.7 .4 software. Table S 4 (see section 2 in Supporting Information) provides calculated indicators, their units and their normalization factor.

\subsection{Application to the Loire-Atlantique case study}

This section deals with data used in this paper concerning the case of Loire-Atlantique. The data were from the year 2012. Although some data correspond to average values over 5 years (between 2011 and 2016), the diagnosis under study mainly refers to the year 2012 .

\subsubsection{Database creation for quarries and recycling facilities in Loire-Atlantique (sellers of basic quality aggregates)}

A list of quarries with their postal addresses in Loire-Atlantique was obtained from the Bureau de Recherches Géologiques et Minières (BRGM) website (BRGM, n.d.). This list of quarries is presented in Supporting Information (Table S 6).

To obtain a list of recycling facilities in Loire-Atlantique containing different types of facilities (as discussed previously) different sources were used and different assumptions were made. The summary of assumptions 
made to create the list of recycling facilities in Loire-Atlantique is presented in the Supporting Information (see Recycling facilities database creation and explanations provided).

\subsubsection{Production capacities and mass ratios of quarries in Loire-Atlantique}

Information regarding the annual authorized production of the quarries was provided on the BRGM website (BRGM, n.d.). However, according to the expert opinions, the amount usually produced is less than the maximum authorized production capacity. The developed model requires actual production of the quarries in a given year, but such information is not provided on the BRGM website. Fortunately, Charier Company provided access to the average annual actual production of its quarries over 5 years (from 2011 to 2016). A linear relationship between actual production and authorized production of Charier Company's quarries (see Fig. S 2 in Supporting Information) was observed. This linear relationship is extrapolated to other quarries in order to obtain their production. It is assumed that this relationship is representative of the economic situation between 2011 and 2016 in the region, as quarries in Charier Company represents approximately one third of the production in the region of Pays de la Loire (based on personal communication with Charier Company). The authorized and actual productions of the quarries in Loire-Atlantique are shown in Supporting Information (Table S 6).

Production proportions of A1, A2 and A3 for each quarry in Loire-Atlantique were not available. Therefore, some assumptions were made to estimate the production volume of each category of aggregates in the quarries. Coefficients $\beta 1, \beta 2$ and $\beta 3$ respectively were estimated from the average of annual production between 2011 and 2016 in Charier Company's quarries (shown in Supporting Information Table S 7).

\subsubsection{Production capacities of recycling facilities in Loire-Atlantique}

There is no available data regarding the production capacities of the recycling facilities, except those obtained from Charier Company for two facilities (7,601 and 6,500 tonnes.year $\left.{ }^{-1}\right)$.

$\mathrm{RCC}$ are assumed to be produced according to market demand, and this demand is assumed proportional to population in each segment. RCC demand was thus calculated at the level of each geographical segment, according to its population. For example, if a segment has $10 \%$ of the population of the Loire Atlantique department, it is assumed to represent $10 \%$ of the demand for RCC. Knowing the number of recycling facilities for each geographical segment, it is possible to calculate an average production capacity by dividing RCC 
demand in a given segment by the number of recycling facilities in the same segment (see Table S 9 in Supporting Information). However, this calculation method can introduce bias, because a facility that is close to a border between two segments, can provide to both of them. This is especially the case for some recycling facilities located close to the border of geographical segment 5 (see Fig. 4) which is the main city of Loire Atlantique, with $50 \%$ of the total population. Segment 5 can be provided from facilities close to its border from geographical segments $1,2,6,7,8$ and 9 . Thus, using an average production capacity by segment would lead to underestimate those close to the borders of segment 5 . Thus, a coefficient was added to the calculation method, as shown in Equation 15:

$$
\operatorname{Prod}_{\mathrm{Ri}}=\mathrm{r} \cdot \frac{D_{R C C 0, m}}{n_{R i, m}}
$$

Equation 15

Where $\operatorname{Prod}_{R i}$ (tonnes.year-1) is the production capacity of recycling facility $i$ and geographical segment $m, D_{R C C 0, m}$ (tonnes.year ${ }^{-1}$ ) the demand for RCC in geographical segment $m, n_{R i, m}$ (integer) is the number of recycling facilities in geographical segment $m, r$ (n.u.) is a coefficient added in order to avoid border effects.

The value of coefficient $r$ was tested with a sensitivity analysis described (see Results).

\subsubsection{Locations of buyers and sellers of basic quality aggregates on the map of Loire-Atlantique}

As explained previously, the map of Loire-Atlantique was divided into 9 geographical segments. The aim was mainly to have similar populations in each geographical segment (see Fig. 4), except geographical segments 4 and 5 which have much higher populations compared to other geographical segments, since they are related to the main cities of Loire-Atlantique (Saint-Nazaire and Nantes respectively). Table S 10 in Supporting Information, details the population of each geographical segment in Fig. 4. Information regarding the total population in Loire-Atlantique is obtained from statistical data for year 2012.

The nine centres of gravities are representative of the BQA buyers in Loire-Atlantique. Locations of the BQA sellers in Loire-Atlantique are marked on the map (Fig. 4) according to the postal codes of the lists of sellers (quarries and recycling facilities presented in Table S 6 in Supporting Information). 


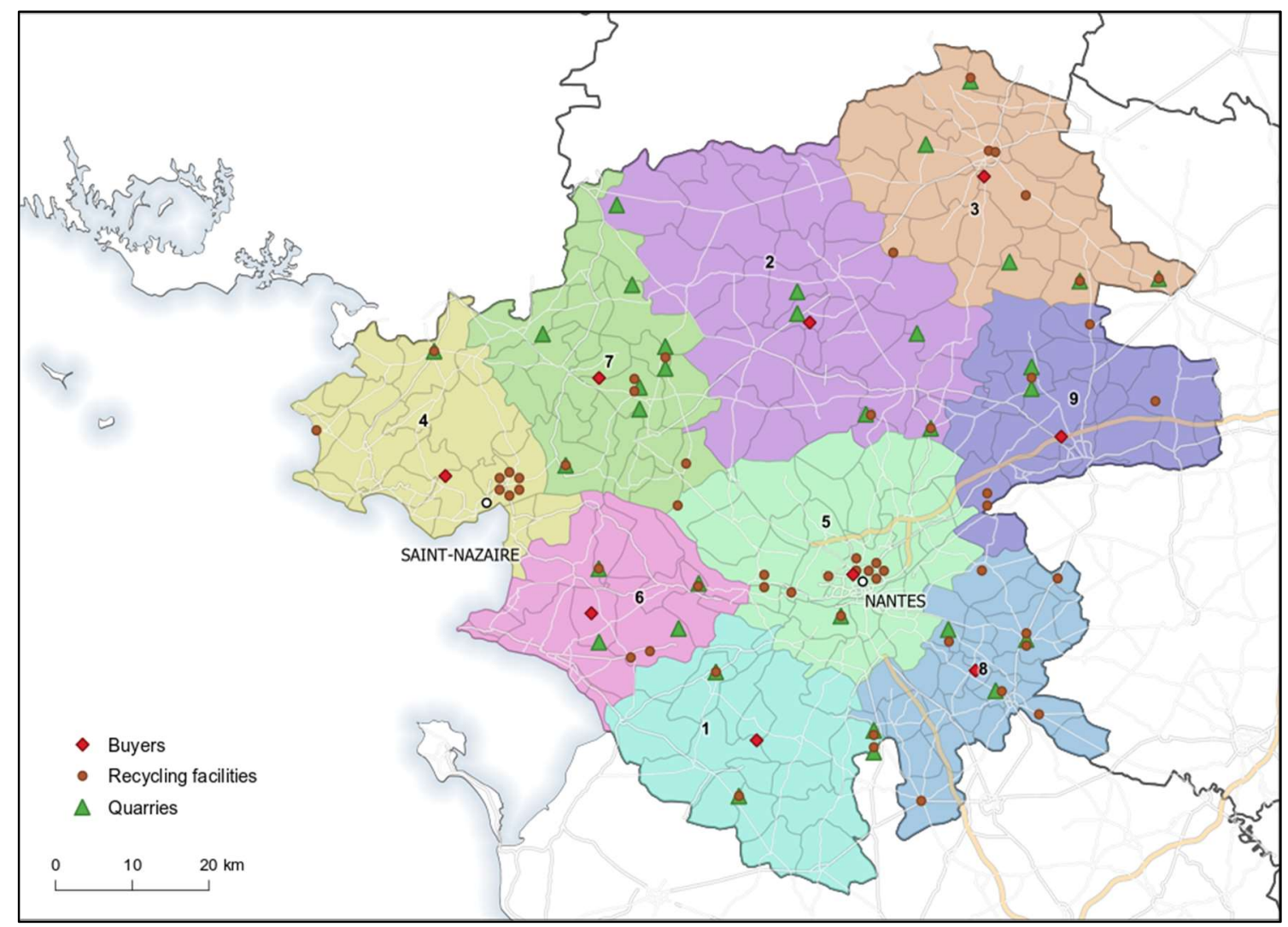

Fig. 4. Map of Loire-Atlantique divided into nine geographical segments, with all sellers (quarries and recycling facilities) and nine construction or demolition site (buyers) as population centre of gravities of each geographical segment in LoireAtlantique, France, using a geographical information system.

As can be noticed in Fig. 4, there are few quarries in geographical segments 4 and 5, which have the highest population density and subsequently are expected to have higher demands for BQAs. Quarries are mainly located in other segments corresponding to areas with low population density. On the contrary, recycling facilities are mainly located in the densely populated areas. They are close to the places where higher CCDW production and BQA demand are expected.

\subsubsection{Productions and consumptions of materials in Loire-Atlantique}

Data from literature, statistics and facilities were used to estimate the production and consumption of materials in the regional CCDW management model (Fig. 2) in Loire-Atlantique in 2012.

A report of the Regional Economic Unit for Construction (CERC) provided a detailed MFA of Loire Atlantique C\&DW in 2012 (CERC, 2013). Data concerning all waste flows and their destinations (landfill, quarry filling, recycling...) are obtained from a previous local report (CERC, 2013) . 
The CERC report estimates that total C\&DW represents 2,455,000 tonnes for the Loire Atlantique region. Amongst them 2,381,000 tonnes are for inert waste (97\%) and 74,000 tonnes for other waste (non-dangerous and dangerous) (CERC, 2013). Detailed tables derived from the CERC report (CERC, 2013) are provided in the Supporting Information (Table S 11 to Table S 16).

In order to figure out the total consumption of materials in the regional CCDW management system in LoireAtlantique in 2012, the CERC database was used as the main source. However, some assumptions were made based on Charier Company's database to obtain some missing data. They are discussed in detail as follows.

The CERC database provides the total consumption of cement concrete in Loire-Atlantique in 2012 from which the total demand for A3 used in cement concrete can be calculated based on Equation 2. The CERC database also provides data on production of bituminous concrete in 2012 in Loire-Atlantique, but not on consumption. Therefore, it was assumed that bituminous concrete is produced up to the amounts that are consumed, which is justified by the fact that bituminous concrete cannot be stored. Indeed, it is produced at temperatures between $100^{\circ} \mathrm{C}$ and $160^{\circ} \mathrm{C}$ and must be warm enough (around $90^{\circ} \mathrm{C}$ ) to be applied as a road layer. As a result, the total demand for A3 used in bituminous concrete is calculated based on Equation 3. Accordingly, the total demand for A3 in 2012 in Loire-Atlantique is obtained from Equation 1.

Subsequently, the total productions of A1 and A2 are estimated from Equation 5, using mass ratios from Table S 7. However, no precise data were found regarding the demands for A1 and A2. The total demands for A1, A2 and A3 from Charier Company's quarries are known (see details Table S 8 in Supporting Information), from which demand proportions, i.e mass ratios for $\gamma_{1}$ and $\gamma_{2}$ are calculated. It is assumed that Charier's mass ratios are representative of all quarries in Loire-Atlantique. Therefore, these mass ratios were used to estimate the total demands for $\mathrm{A} 1$ and $\mathrm{A} 2, \mathrm{D}_{\mathrm{A} 1}$ and $\mathrm{D}_{\mathrm{A} 2}$ respectively, in Loire-Atlantique in 2012.

In addition, the CERC database provides the total demand for RCC, $\mathrm{D}_{\mathrm{RCC}}$, in Loire-Atlantique in 2012 that is $\mathrm{D}_{\mathrm{RCC}}=129,600$ tonnes.

As BQAs can be provided by both quarries and recycling facilities, the total demand for BQAs, DBQA, in the BQA market (BQA market Fig. 2) in Loire-Atlantique in 2012 is the summation of $\mathrm{D}_{\mathrm{A} 1}$ and $\mathrm{D}_{\mathrm{RCC}}$ in 2012 in 
Loire-Atlantique. Subsequently, the total demand of each of the nine buyers for BQAs in each of the nine geographical segments (see Fig. 4) was estimated from Equation 10.

\section{RESULTS AND DISCUSSION}

\subsection{MFA of the CCDW management in Loire-Atlantique}

Fig. 5 shows the material flows of the departmental C\&D inert waste management as inputs to destinations in Loire-Atlantique in 2012 derived from the CERC report (CERC, 2013) (for detailed numbers, see Table S 11 to Table S 16 in Supporting Information). Fig. 5 shows that inert C\&DW are mainly composed of excavated soil $(1,735,000$ tonnes) and of a mix of materials in second position (301,100 tonnes). No information was given about its composition.

Recycling platforms (see Table S 14 in appendix) do not exclusively receive 129,600 tonnes of CCDW, but also receive amounts of waste gravels (71,700 tonnes), asphalt (9,800 tonnes), excavated soil (17,400 tonnes) and mixed materials (21,100 tonnes), for a total of 120,000 tonnes of additional material. The amount of CCDW produced in the Loire Atlantique department is $\mathrm{P}_{\mathrm{CCDW}}=144,000$ tonnes, whereas the amount of RCC exiting the recycling platforms is $\mathrm{D}_{\mathrm{RCC}}=129,600$ tonnes (see Table $\mathrm{S} 14$ obtained from the CERC report). The amount of landfilled CCDW is given $\mathrm{L}_{\mathrm{CCDW}}=7,200$ tonnes, and the CERC report also specifies that 7,200 tonnes of CCDW are sent to temporary storage. However, it is assumed that this amount was calculated to reach mass conservation of CCDW but that it may correspond to material loss in the recycling platform, due to its technical efficiency (see Fig. 2), defined as defined as the ratio of output product out of input material. Consequently, the technical efficiency of recycling platforms is estimated to be $95 \%$. 


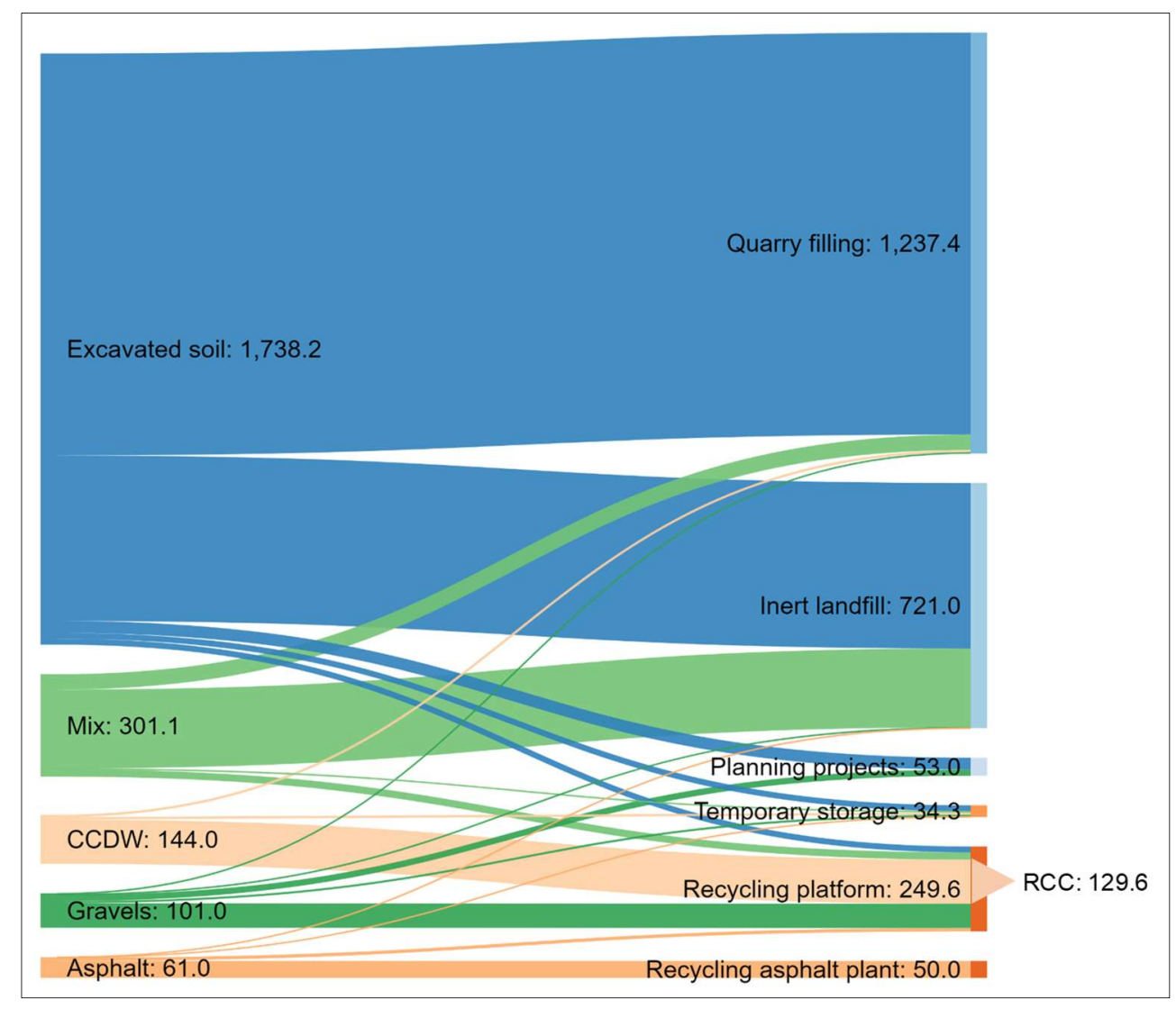

Fig. 5. MFA of inert C\&DW management in Loire-Atlantique in 2012: types of input flows to their destinations. All units are kilotonnes ( $k t$ )

Mass flows obtained for the system model are summarized in Fig. 2. As concerns natural aggregates, approximately 4,908,200 tonnes of natural aggregates are produced in the Loire Atlantique department. Tertiary aggregates (A3) calculated from amounts of cement concrete $\left(\mathrm{D}_{\mathrm{A} 3 \mathrm{CC}}=1,327,700\right.$ tonnes $)$ and bituminous concrete $\left(\mathrm{D}_{\mathrm{A} 3 \mathrm{BC}}=812,300\right.$ tonnes $)$ according to Equation 1-Equation 3, are found to be the largest amount of natural aggregates produced (PA3 $=2,140,000$ tonnes). The amount of BQA available in 2012 is constituted by $\mathrm{P}_{\mathrm{A} 1}=1,850,400$ tonnes (calculated from Equation 4) and $\mathrm{D}_{\mathrm{RCC}}=129,600$ tonnes, whereas the demand for BQA market is estimated below this production with $\mathrm{D}_{\mathrm{BQA}}=1,806,300$ tonnes. Finally, the market share for BQA in Loire Atlantique in 2012 is found to be $f_{\mathrm{RCC} 0}=7.2 \%(129,600$ tonnes out of $1,806,300$ tonnes $)$ for recycled materials. Despite their high market share $f_{\mathrm{A} 10}=92.8 \%$, A1 are produced in excess compared to the market demand, and the addition to stock of $\mathrm{A} 1$ in quarries is $\Delta \mathrm{S}_{\mathrm{A} 10}=173,600$ tonnes in 2012. 


\subsection{Sensitivity analysis on production capacities of recycling facilities}

As production capacities of recycling facilities are not known, a sensitivity analysis on the $r$ coefficient (see Equation 15) was conducted. When production capacities are expected to be very flexible (high value of $r$ coefficient), the amount of materials transported is found to decrease (Fig. 6), indicating that transport distances decrease, especially those concerning the highest demand segments (B4 and B5). Recycling facilities closest to the highest market demand remain the only providers, which explains that result: this is showed by an increase of the number of inactive recycling facilities (those that do not sell any material, see Erreur ! Source du renvoi introuvable. in Supporting Information). When the production capacities coefficient is above 5, the number of inactive facilities remains constant at 39 out of 55 recycling facilities identified in the Loire Atlantique department.

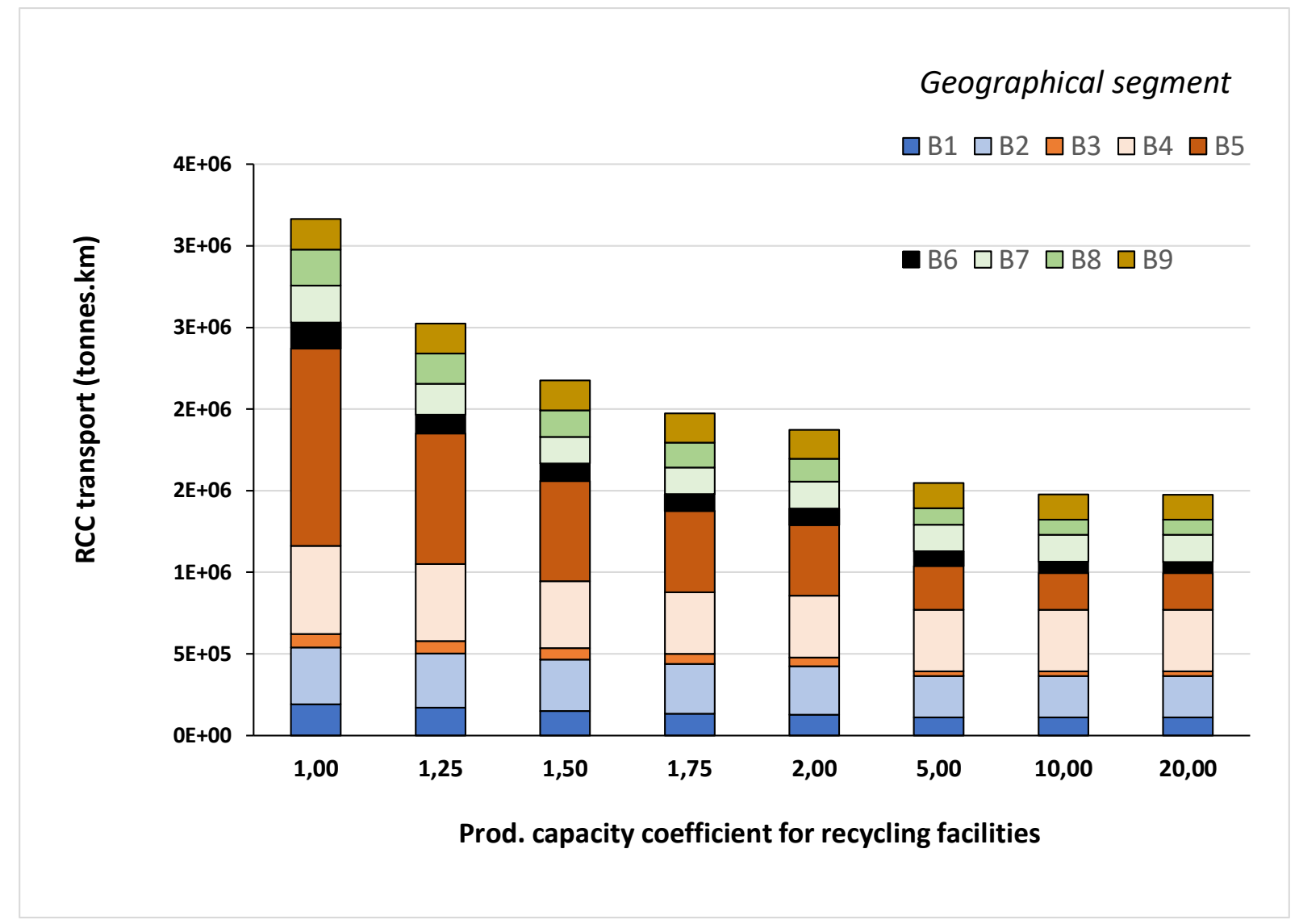

Fig. 6. Effect of production capacities of recycling facilities on transported amounts for each geographical segment 


\subsection{Environmental impacts at territorial scale}

Fig. 7 shows the relative contributions of each activity for each impact category considered for the BQA management system. In that figure, each activity gathers on-site and off-site related productions. The two most important contributing processes are transportation and A1 production which each range between $25 \%$ and $70 \%$ for all impacts except for water resource depletion. The highest contribution of the landfilling process is for the land use indicator, but even then, its contribution is very small, below 5\%. Although similar to the quarry process, the recycling process is always a smaller contributor, due to the small amounts of CCDW that are recycled. Storage of A1 in quarries does not appear as an important contributor to any environmental impact.

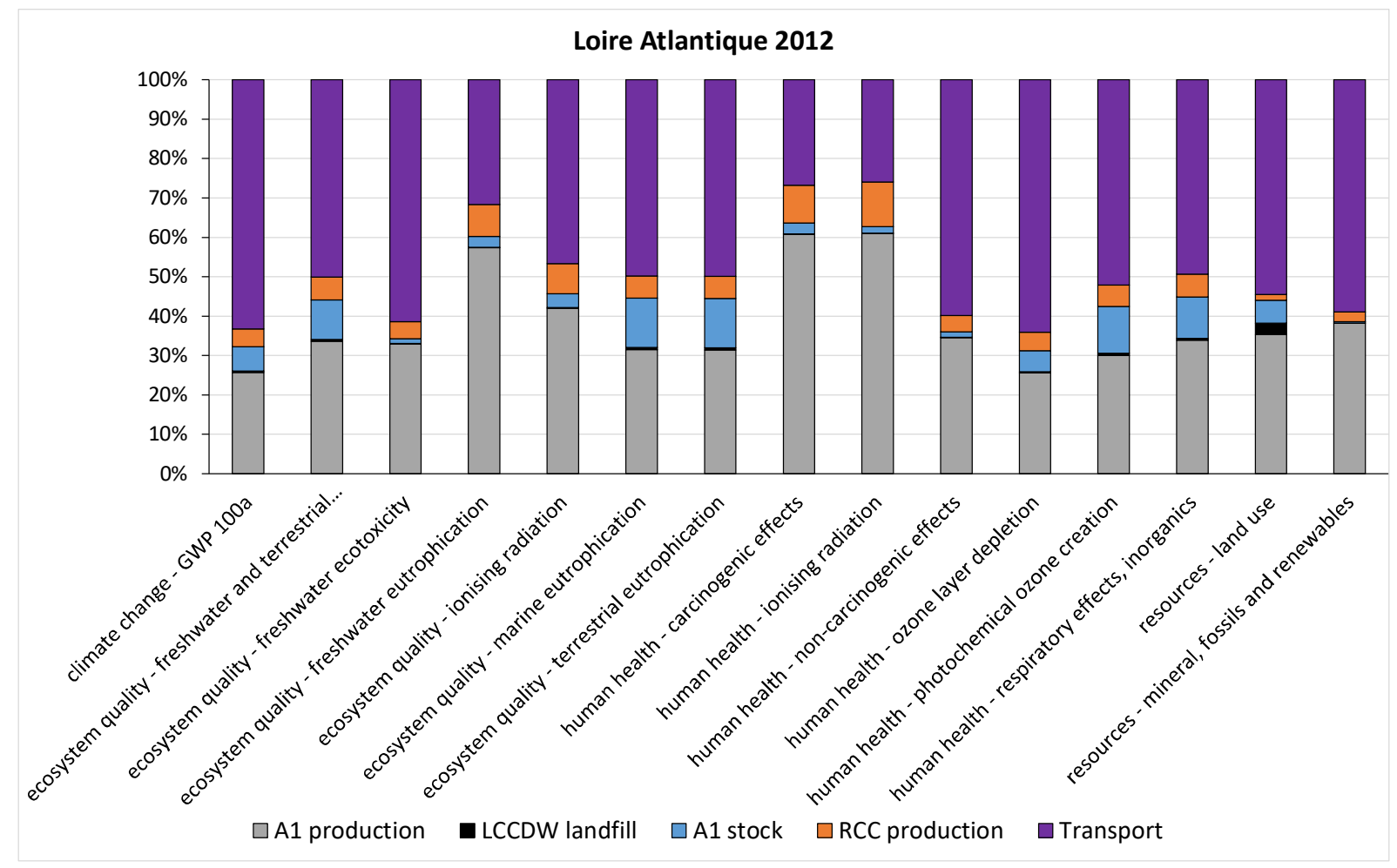

Fig. 7. Contributions of processes contributions including background off-site activities to environmental impacts for basic quality aggregate management system in Loire Atlantique in 2012

Fig. 8 provides the same results as Fig. 7, but only accounting for the on-site contribution of each activity. Onsite activities are considerably reduced, especially A1 production, showing that their impacts mainly occur offsite. The main contributor to impacts of A1 production is electricity production, which corresponds to the French average mix. Impacts of off-site activities occurring in France are not very important except for ionising 
radiations indicators. These indicators are totally driven by the French nuclear electricity production and thus represent electricity consumed in A1 and RCC production. A better model including local electricity production would probably increase the on-site impacts of A1 production, especially because of a local power plant fuelled with coal. Transports are confirmed being the main on-site contribution to all environmental impacts.

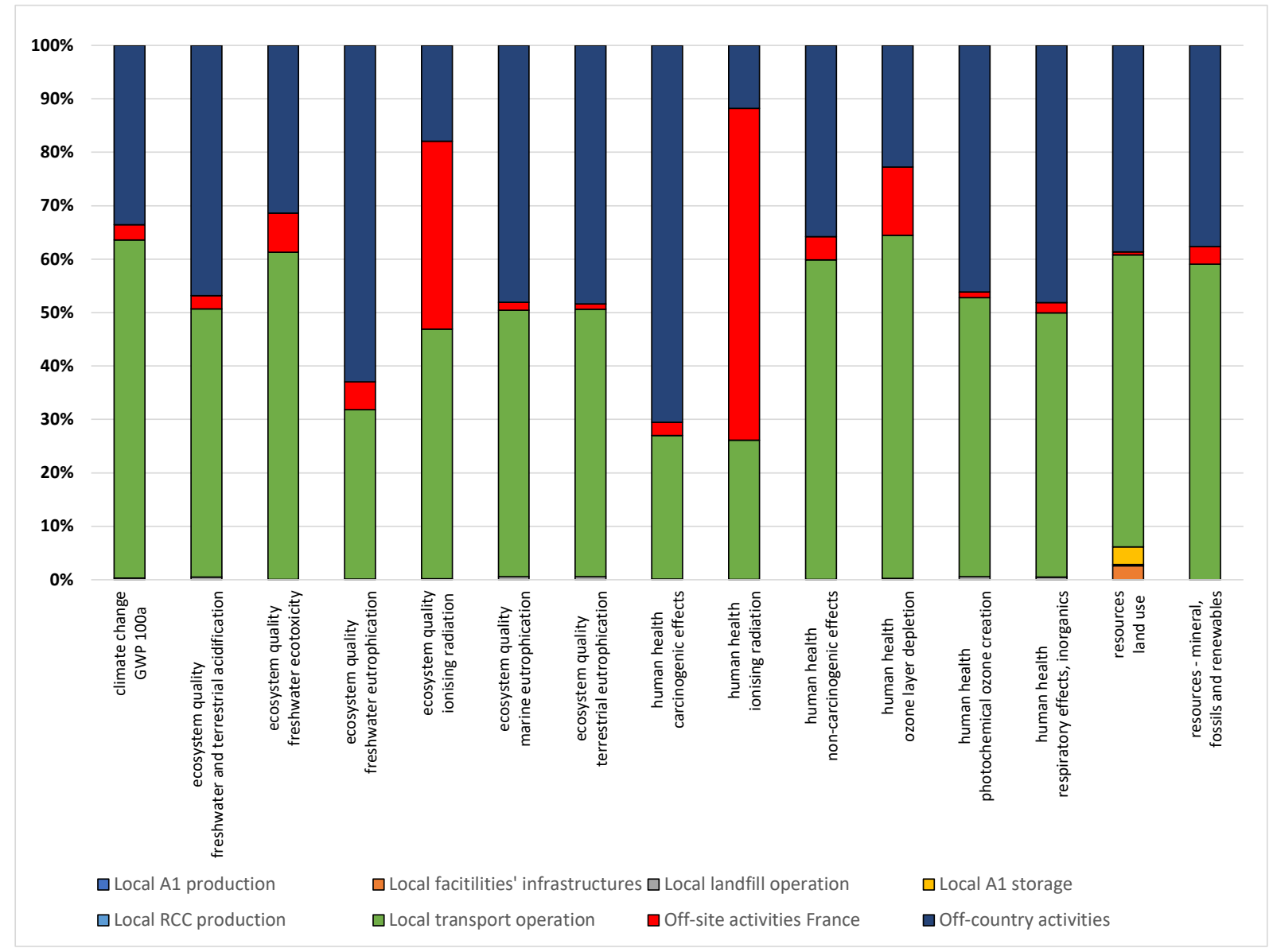

Fig. 8. Contributions of processes of on and off-site activities to environmental impacts for BQA management system in Loire Atlantique in 2012

\section{DISCUSSION}

The decision-based territorial MFA of Loire Atlantique shows that, the majority of the CCDW produced is already recycled, and thus very little CCDW is available for sale especially when compared to existing A1 stocks (Fig. 2 and Fig. 5). However, the data collected for that MFA are based on publicly available market sales for 
RCC and A1, as well as on admissions of CCDW into landfill and recycling facilities. It seems that many local companies have diversified activities in such fields as building demolition, quarries, recycling facilities, earthworks and road construction, as well as inert landfill facilities. This local market structure favours internal recovery, reuse or recycling of CCDW. These quantities do not show up on the market. Interviews with many stakeholders confirmed that an important part of CCDW was not going through the market but was internally recovered, reused or recycled instead.

The results (Fig. 8) show that local transport is the main contributor to on-site environmental impacts. In addition, the sensitivity analysis of the production capacities of recycling facilities, showed that increasing their production would lead to a considerable reduction of transported amounts. Indeed, facilities with high capacity, close to high demand segments, would be privileged by buyers. The sensitivity analysis was conducted in order to test the influence of this unknown parameter, and it is found to be very influent. These results reveal the possibility of land planning scenarios concerning inert waste recycling facilities: in Loire Atlantique territory, a PRPGD enabling high production capacities for recycling facilities located closest to the main cities with the highest BQA demand, can divide the need for transport by a factor of 2 .

These results cannot be generalised to other geographical area. First, the size of the area studied is an important modelling question. Indeed, if the area is too small border effects can be expected, i.e. materials could be imported or exported in quarries or recycling platforms outside the studied area but close to the border. This was not an issue for the case study, as the CERC report (CERC, 2013) estimates that imports and exports of inert waste is less than $1 \%$. In a different situation, it would be important to increase the size of the geographical area considered to limit border effects, or to include in the database outside facilities which are close to the border. Subject to this precaution, the environmental model for CCDW management developed in this article can be applied to any geographical area by using local data and considering local conditions. Second, the presented results are very dependent on existing local facilities and local CCDW and A1 resources. Indeed, CCDW resource was found a particularly small resource compared to A1, due to an important number of quarries in the territory. Although the model seems applicable to other geographical areas, results would certainly differ.

The herein developped approach differs from existing territorial LCAs by the method used to define the system model. The foreground system model is defined according to an action perimeter, located inside the studied 
geographical area, and inside which there are physical or economic relationships between flows. In that way, the foreground system model is obtained in accordance with an LCA approach (Frischknecht, 1998) considering an objective, an action perimeter, intermediary flows between production processes and possibly economic relationships through markets. The background system includes all flows related to the initial foreground system that are out of the action perimeter, however their exact location is unknow, and they are by default, considered off-site.

It is important to notice that the developped method provides a picture of a situation for a given year, thus it is not a dynamic method. To evolve towards temporal simulations, data collection for actual stocks of different materials inside quarries and recycling platforms would be required. Such data are not available. Assuming that 2012 is a starting point, the evolution of stocks could be estimated if regular data on waste production and destinations were produced. Indeed, CERC regularly collects data on economic markets (monthly), but surveys on waste management are not that frequent. These data are difficult to obtain, and several assumptions and extrapolations from a reduced set of data mainly obtained from the Charier Company were necessary. Real data would consolidate the model, and provide more accuracy for future waste management scenarios. If this approach were to be used by local authorities, it is recommended to develop a local observatory in order to collect these data to feed the herein developed model. This would facilitate the elaboration of strategies for C\&DW management.

\section{CONCLUSION}

In this paper a decision-based territorial LCA was conducted. It differs from existing territorial LCAs, as it focuses on a specific system concerning specific stakeholders. This approach proves to be very useful for the stakeholders concerned because it provides insights for future actions.

The case study in the Loire Atlantique department shows that very little Cement Concrete Demolition Waste (CCDW) was actually produced in 2012 . Thus, although $90 \%$ of what is available on the market is recovered as Recycled Cement Concrete (RCC) and used as a secondary resource for Basic Quality Aggregates (BQA), the recycling activity is not found to be significant. However, these results do not account for internal recycling in construction companies, which could be much more important than commonly expected, according to what 
experts say. Despite a small amount of available secondary resource, the primary resource of BQA (A1) is overproduced compared to the market demand, because these primary and secondary BQA resources are both constrained products: their production respectively depends on High Quality Aggregate production for A1 and building demolition for RCC. The environmental impacts of the BQA management system are found to be very dependent on off-site activities. For on-site activities, they are mainly driven by the transport of these materials from production sites to construction sites and/or landfills. Thanks to a sensitivity analysis on the production capacity of recycling facilities, it was shown that there was an important land planning issue. Compared to the current situation in 2012, with small recycling facilities distributed all over the Loire Atlantique department, a concentration of fewer recycling facilities with high authorised production capacities in main cities, close to where CCDW is mainly produced, would divide transport needs by 2 and thus considerably reduce environmental impacts.

The model of the current 2012 situation could allow to investigate how an increase in the market share of recycled aggregates would affect the environmental performance of the aggregate production and management in the Loire Atlantique department. This requires developing a local market mechanism model to reflect the decision procedures of the buyers making choices between the two sources of basic quality aggregates (natural and recycled) in the market. This is the purpose of a next paper.

\section{Acknowledgments}

Funds for the research and education chair of civil engineering and eco-construction were provided by the Chamber of Trade and Industry of Nantes and Saint-Nazaire cities, the CARENE (urban agglomeration of SaintNazaire), Charier, Architectes Ingénieurs Associés, Vinci construction, the Regional Federation of Buildings, and the Regional Federation of PublicWorks. Donators were not involved in the research design, the writing and the decision to submit this article. The authors would like to thank them all for their financial support.

Authors would also like to thanks the CERC of Pays de la Loire for providing the access local MFA of construction waste and resources. 


\section{REFERENCES}

Augiseau, V., Barles, S., 2017. Studying construction materials flows and stock: A review. Resour. Conserv. Recycl. 123, 153-164. https://doi.org/10.1016/j.resconrec.2016.09.002

Barles, S., 2010. Society, energy and materials: the contribution of urban metabolism studies to sustainable urban development issues. J. Environ. Plan. Manag. 53, 439-455. https://doi.org/10.1080/09640561003703772

Behera, M., Bhattacharyya, S.K., Minocha, A.K., Deoliya, R., Maiti, S., 2014. Recycled aggregate from C\&D waste $\&$ its use in concrete - A breakthrough towards sustainability in construction sector: A review. Constr. Build. Mater. 68, 501-516. https://doi.org/10.1016/j.conbuildmat.2014.07.003

Bidstrup, M., Pizzol, M., Schmidt, J.H., 2015. Life Cycle Assessment in spatial planning - A procedure for addressing systemic impacts. J. Clean. Prod. 91, 136-144. https://doi.org/10.1016/j.jclepro.2014.12.027

Blengini, G.A., Garbarino, E., 2010. Resources and waste management in Turin (Italy): the role of recycled aggregates in the sustainable supply mix. J. Clean. Prod. 18, 1021-1030. https://doi.org/10.1016/j.jclepro.2010.01.027

brgm, 2016. Observatoire des matériaux. [Observations of materials] [WWW Document]. URL http://materiaux.brgm.fr/Erreur.aspx?aspxerrorpath=/CartesExploitations.aspx (accessed 4.10.17).

BRGM, n.d. InfoTerre : le portail d'accès aux données scientifiques du BRGM | BRGM [WWW Document]. URL https:/www.brgm.fr/production-scientifique/donnees-services-numeriques/infoterre-portail-accesdonnees (accessed 4.3.19).

CERC, 2013. Etude sur les volumes et les flux déchets et matériaux recyclés du BTP., Observation des “déchets et du recyclage" du BTP. Cellule Economique Régionale de la Construction, Nantes, France.

Chester, M., Pincetl, S., Allenby, B., 2012. Avoiding unintended tradeoffs by integrating life-cycle impact assessment with urban metabolism. Curr. Opin. Environ. Sustain., Human settlements and industrial systems 4, 451-457. https://doi.org/10.1016/j.cosust.2012.08.004

CNR, 2013. Enquête Longue distance 2012. Comité National Routier, Paris, France.

DoGeocodeur, n.d. DoGeocodeur [WWW Document]. URL https://dogeo.fr/_apps/DoGeocodeur/ (accessed 3.14.18).

DREAL, 2019. Le Portail numérique des ICPE - Inspection des Installations Classées [WWW Document]. URL http://www.installationsclassees.developpement-durable.gouv.fr/Le-Portail-numerique-des-ICPE.html (accessed 4.3.19).

Etxeberria, M., Marí, A.R., Vázquez, E., 2007. Recycled aggregate concrete as structural material. Mater. Struct. 40, 529-541. https://doi.org/10.1617/s11527-006-9161-5

FFB, 2016. Déchets de chantier du bâtiment : tri des déchets. [Construction waste: sorting of wastes]. [WWW Document]. URL http://www.dechets-chantier.ffbatiment.fr/ (accessed 4.10.17).

Frischknecht, R., 1998. Life cycle inventory analysis for decision-making: Scope-Dependent Inventory System Models and Context-Specific Joint Product Allocation. SwissFederal Institute of Technology Zurich. 
Goldstein, B., Birkved, M., Quitzau, M.-B., Hauschild, M., 2013. Quantification of urban metabolism through coupling with the life cycle assessment framework: concept development and case study. Environ. Res. Lett. 8, 035024. https://doi.org/10.1088/1748-9326/8/3/035024

Joint Research Centre, 2011. Recommendations for Life Cycle Impact Assessment in the European context (No. EUR 24571 EN-2011), International Reference Life Cycle Data System (ILCD) handbook. European Commission, Luxembourg.

JORF, 2015a. Loi n 2015-991 du 7 août 2015 portant nouvelle organisation territoriale de la République, 2015 991.

JORF, 2015b. Loi n 2015-992 du 17 août 2015 relative à la transition énergétique pour la croissance verte Version consolidée au 02 décembre 2016, 2015-992.

Kennedy, C., Cuddihy, J., Engel-Yan, J., 2007. The Changing Metabolism of Cities. J. Ind. Ecol. 11, 43-59. https://doi.org/10.1162/jie.2007.1107

Loiseau, E., Aissani, L., Le Féon, S., Laurent, F., Cerceau, J., Sala, S., Roux, P., 2018. Territorial Life Cycle Assessment (LCA): What exactly is it about? A proposal towards using a common terminology and a research agenda. J. Clean. Prod. 176, 474-485. https://doi.org/10.1016/j.jclepro.2017.12.169

Loiseau, E., Junqua, G., Roux, P., Bellon-Maurel, V., 2012. Environmental assessment of a territory: An overview of existing tools and methods. J. Environ. Manage. 112, 213-225. https://doi.org/10.1016/j.jenvman.2012.07.024

Loiseau, E., Roux, P., Junqua, G., Maurel, P., Bellon-Maurel, V., 2014. Implementation of an adapted LCA framework to environmental assessment of a territory: important learning points from a French Mediterranean case study. J. Clean. Prod. 80, 17-29. https://doi.org/10.1016/j.jclepro.2014.05.059

Loiseau, E., Roux, P., Junqua, G., Maurel, P., Bellon-Maurel, V., 2013. Adapting the LCA framework to environmental assessment in land planning. Int. J. Life Cycle Assess. 18, 1533-1548. https://doi.org/10.1007/s11367-013-0588-y

Moreno Ruiz, E., Levova, T., Reinhard, J., Valsasina, L., Bourgault, G., Wernet, G., 2016. Documentation of changes implemented in the ecoinvent database v3.3. Ecoinvent, Zürich.

Pacheco-Torgal, F., Tam, V., Labrincha, J., Ding, Y., Brito, J. de, 2013. Handbook of Recycled Concrete and Demolition Waste. Elsevier.

Pepe, M., 2015. A conceptual model to design recycled aggregate concrete for structural applications. Università Degli Studi Di Salerno.

Pincetl, S., Bunje, P., Holmes, T., 2012. An expanded urban metabolism method: Toward a systems approach for assessing urban energy processes and causes. Landsc. Urban Plan. 107, 193-202. https://doi.org/10.1016/j.landurbplan.2012.06.006

Sandberg, N.H., Sartori, I., Heidrich, O., Dawson, R., Dascalaki, E., Dimitriou, S., Vimmr, T., Filippidou, F., Stegnar, G., Šijanec Zavrl, M., Brattebø, H., 2016. Dynamic building stock modelling: Application to 11 European countries to support the energy efficiency and retrofit ambitions of the EU. Supplementary material. Energy Build. https://doi.org/10.1016/j.enbuild.2016.05.100

Senga Kiessé, T., Ventura, A., van der Werf, H.M.G., Cazacliu, B., Idir, R., Andrianandraina, 2017. Introducing economic actors and their possibilities for action in LCA using sensitivity analysis: Application to hemp-based insulation products for building applications. J. Clean. Prod. 142, 3905-3916. https://doi.org/10.1016/j.jclepro.2016.10.069 
Spielmann, M., Bauer, C., Dones, R., Tuchschmid, M., 2007. 14_Transport Services (No. ecoinvent report $\left.\mathrm{n}^{\circ} 14\right)$. Paul Scherre Institute (PSI) and ESU-services LtD, Villigen and Uster.

Thorn, N.H., Brown, S.F., 1989. 17 - The mechanical properties of unbound aggregates from various sources, in: Jones, R.H., Dawson, A.R. (Eds.), Unbound Aggregates in Roads. Butterworth-Heinemann, pp. 130 142. https://doi.org/10.1016/B978-0-408-04355-7.50024-8

Ventura, A., 2020. Solution oriented LCAs in a geographical context | AScUS (un)Conference, in: Actionable Science for Urban Sustainability. Presented at the AScUS, Segovia (Spain).

Ventura, A., Monéron, P., Jullien, A., 2008. Environmental Impact of a Binding Course Pavement Section, with Asphalt Recycled at Varying Rates: Use of Life Cycle Methodology. Road Mater. Pavement Des. 9, 319-338. 


\section{Supporting Information}

\section{ACRONYMS AND SYMBOLS}

Table S 1. Acronyms

\begin{tabular}{|l|l|}
\hline Acronym & \multicolumn{1}{c|}{ Description } \\
\hline A3 & High Quality (tertiary) Aggregates from quarries \\
\hline A2 & Medium Quality (secondary) Aggregates from quarries \\
\hline A1 & Basic Quality (primary) Aggregates from quarries \\
\hline BC & Bituminous Concrete \\
\hline BQA & Basic Quality Aggregates from both quarries or recycling facilities \\
\hline CC & Cement Concrete \\
\hline CCDW & Cement Concrete Demolition Waste \\
\hline C\&DW & Construction and Demolition Waste \\
\hline ILCD & International Reference Life Cycle Data System \\
\hline LCA & Life Cycle Assessment \\
\hline LCIA & Life Cycle Impact Assessment \\
\hline PRPGD & $\begin{array}{l}\text { Plan Régional de Prévention et de Gestion des Déchets (Regional Progam for Waste Prevention } \\
\text { and Management) }\end{array}$ \\
\hline MFA & Material Flow Analysis \\
\hline RCC & Recycled Cement Concrete: Basic Quality Aggregates from recycling facilities \\
\hline
\end{tabular}

Table S 2. Symbols in equations

\begin{tabular}{|l|l|l|}
\hline Symbol & \multicolumn{1}{|c|}{ Unit } & \multicolumn{1}{c|}{ Description } \\
\hline $\mathrm{D}_{\mathrm{A}}$ & tonne.year $^{-1}$ & Annual amount of market Demand for all aggregates \\
\hline $\mathrm{D}_{\mathrm{BQA}}$ & tonne.year $^{-1}$ & Annual amount of market Demand for BQA \\
\hline $\mathrm{D}_{\mathrm{A} 3 \mathrm{CC}}$ & tonne.year $^{-1}$ & Annual amount of market Demand for A3 to be used in Cement Concrete \\
\hline $\mathrm{D}_{\mathrm{A} 3 \mathrm{BC}}$ & tonne.year $^{-1}$ & Annual amount of market Demand for A3 to be used in Bituminous Concrete \\
\hline $\mathrm{D}_{\mathrm{A} 3}$ & tonne.year $^{-1}$ & Annual amount of market Demand for A3 (total) \\
\hline $\mathrm{D}_{\mathrm{A} 2}$ & tonne.year $^{-1}$ & Annual amount of market Demand for A2 \\
\hline $\mathrm{D}_{\mathrm{A} 1}$ & tonne.year $^{-1}$ & Annual amount of market Demand for A1 \\
\hline $\mathrm{D}_{\mathrm{RCC}}$ & tonne.year $^{-1}$ & Annual amount of market Demand for RCC \\
\hline $\mathrm{P}_{\mathrm{A} 3}$ & tonne.year $^{-1}$ & Annual amount of produced A3 \\
\hline $\mathrm{P}_{\mathrm{A} 2}$ & tonne.year $^{-1}$ & Annual amount of produced A2 \\
\hline $\mathrm{P}_{\mathrm{A} 1}$ & tonne.year $^{-1}$ & Annual amount of produced A1 \\
\hline $\mathrm{P}_{\mathrm{CCDW}}$ & tonne.year $^{-1}$ & Annual amount of produced CCDW \\
\hline $\mathrm{L}_{\mathrm{CCDW}}$ & tonne.year $^{-1}$ & Annual amount of produced CCDW sent to Landfill \\
\hline $\mathrm{M}_{\mathrm{A} 3 \mathrm{CC}}$ & tonne.m $^{-3}$ & Mass intensity of A3 in Cement Concrete \\
\hline $\mathrm{D}_{\mathrm{A} 3 \mathrm{CC}}$ & $\mathrm{m}^{3} . y e a r^{-1}$ & Annual amount of A3 market Demand for Cement Concrete \\
\hline $\mathrm{M}_{\mathrm{A} 3 \mathrm{BC}}$ & n.u (mass ratio) & Mass intensity of A3 in Bituminous Concrete \\
\hline $\mathrm{D}_{\mathrm{BC}}$ & $\mathrm{m}^{3} \cdot$ year $^{-1}$ & Annual amount of market Demand for Bituminous Concrete \\
\hline$\beta_{3}$ & n.u (mass ratio) & Average mass ratio of A3 produced in a quarry \\
\hline$\beta_{2}$ & n.u (mass ratio) & Average mass ratio of A2 produced in a quarry \\
\hline$\beta_{1}$ & n.u (mass ratio) & Average mass ratio of A1 produced in a quarry \\
\hline $\mathrm{TRE}$ & n.u (mass ratio) & Mass ratio of loss material in the recycling process (Technical efficiency of \\
\hline
\end{tabular}


Supporting Information for:

Mousavi, Ventura and Antheaume. Decision-based territorial Life Cycle Assessment for the Management of Cement Concrete Demolition Waste. Waste Management and Research.

\begin{tabular}{|c|c|c|}
\hline Symbol & Unit & Description \\
\hline & & the recycling facility) \\
\hline F1 & n.u (mass ratio) & Fraction of environmental impact of the quarry allocated to A1 aggregates \\
\hline F2 & n.u (mass ratio) & Fraction of environmental impact of the quarry allocated to A2 aggregates \\
\hline F3 & n.u (mass ratio) & Fraction of environmental impact of the quarry allocated to A3 aggregates \\
\hline $\mathrm{F}_{\mathrm{i}}$ & integer & Number of facilities producing BQA in the studied geographical area \\
\hline $\mathrm{F}_{\mathrm{i}, \mathrm{m}}$ & integer & Number of facilities producing BQA in the geographical segment $\mathrm{m}$ \\
\hline $\mathrm{R}_{\mathrm{i}}$ & integer & $\begin{array}{l}\text { Number of recycling facilities producing RCC in the studied geographical } \\
\text { area }\end{array}$ \\
\hline $\mathrm{R}_{\mathrm{i}, \mathrm{m}}$ & integer & Number of recycling facilities producing RCC in the geographical segment $\mathrm{m}$ \\
\hline $\mathrm{Q}_{\mathrm{i}}$ & integer & Number of quarries producing A1 in the studied geographical area \\
\hline $\mathrm{Q}_{\mathrm{i}, \mathrm{m}}$ & integer & Number of quarries producing A1 in the geographical segment $\mathrm{m}$ \\
\hline $\mathrm{L}_{\mathrm{i}}$ & integer & $\begin{array}{l}\text { Number of landfill facilities receiving CCDW in the studied geographical } \\
\text { area }\end{array}$ \\
\hline $\mathrm{L}_{\mathrm{i}, \mathrm{m}}$ & integer & Number of landfill facilities receiving CCDW in the geographical segment $\mathrm{m}$ \\
\hline $\mathrm{d}_{\mathrm{i}, \mathrm{m}}$ & $\mathrm{km}$ & $\begin{array}{l}\text { Distance between a facility } i \text { and the population centre of gravity of } \\
\text { geographical segment } \mathrm{m}\end{array}$ \\
\hline $\mathrm{TD}_{\mathrm{BQA}}$ & tonne.kilometre & $\begin{array}{l}\text { total ton-kilometer resulting from the transport of BQA to buyers from } \\
\text { different facilities in the geographical area }\end{array}$ \\
\hline $\mathrm{i}$ & integer & $\begin{array}{l}\text { Index indicating a facility producing BQA (either landfill, quarry or recycling } \\
\text { facility) }\end{array}$ \\
\hline $\mathrm{j}$ & integer & $\begin{array}{l}\text { Index indicating a unitary sector according to the available population } \\
\text { geographical database in the studied geographical area }\end{array}$ \\
\hline $\mathrm{m}$ & integer & Index indicating a geographical segment in the studied geographical area \\
\hline Pop & integer & Total population in the studied geographical area \\
\hline $\mathrm{X}_{\mathrm{m}}$ & $\mathrm{km}$ & $\begin{array}{l}\text { Coordinate: } \mathrm{X} \text { axis position of population centre of gravity in geographical } \\
\text { segment } \mathrm{m}\end{array}$ \\
\hline$Y_{m}$ & $\mathrm{~km}$ & $\begin{array}{l}\text { Coordinate: } \mathrm{Y} \text { axis position of population centre of gravity in geographical } \\
\text { segment } \mathrm{m}\end{array}$ \\
\hline
\end{tabular}


Supporting Information for:

Mousavi, Ventura and Antheaume. Decision-based territorial Life Cycle Assessment for the Management of Cement Concrete Demolition

Waste. Waste Management and Research.

\section{DETAILS OF DATA USED FOR LIFE CYCLE ASSESSMENT}

Table S 3. Average composition of trucks' engines in 2012 in France

\begin{tabular}{|l|l|}
\hline \multicolumn{1}{|c|}{ Type of engine } & Percentage of lorries \\
\hline EURO 0,1 and 2 & $2.6 \%$ \\
\hline EURO 3 & $15.6 \%$ \\
\hline EURO 4 & $29.3 \%$ \\
\hline EURO 5 & $52.5 \%$ \\
\hline
\end{tabular}

Table S 4. LCIA methods used for calculating different environmental impact indicators and related normalization factors.

\begin{tabular}{|l|l|r|}
\hline \multicolumn{1}{|c|}{ Impact category } & Reference unit & \multicolumn{1}{c|}{$\begin{array}{c}\text { Normalization factor JRC EU } \\
\mathbf{2 7 , 2 0 1 0} \text { (person.year-1 }^{-1}\end{array}$} \\
\hline Acidification & Mole H+ eq. & 47.3 \\
\hline Climate change & kg CO2 eq. & $9,220.0$ \\
\hline Freshwater ecotoxicity & CTUe & $8,740.0$ \\
\hline Freshwater eutrophication & kg P eq. & 1.48 \\
\hline Human toxicity - carcinogenics & CTUh & $3.69 \mathrm{E}-5$ \\
\hline Human toxicity - non-carcinogenics & CTUh & $5.33 \mathrm{E}-4$ \\
\hline Ionizing radiation - ecosystems & CTUe & - \\
\hline Ionizing radiation - human health & kg U235 eq. & $1,130.0$ \\
\hline Land use & kg SOC & $74,800.0$ \\
\hline Marine eutrophication & kg N eq. & 16.9 \\
\hline Ozone depletion & kg CFC-11 eq. & 0.02 \\
\hline Particulate matter/Respiratory inorganics & kg PM2.5 eq. & 3.8 \\
\hline Photochemical ozone formation & kg C2H4 eq. & 31.7 \\
\hline Resource depletion - mineral, fossils and renewables & kg Sb eq. & 0.1 \\
\hline Resource depletion - water & m3 & 81.4 \\
\hline Terrestrial eutrophication & Mole N eq. & 176.0 \\
\hline
\end{tabular}


3 DETAILS OF CALCULATED TRANSPORT DISTANCES BETWEEN FACILITIES AND CENTRE OF GRAVITY OF

\section{GEOGRAPHICAL SEGMENTS}

Table S 5. Distances $(\mathrm{km})$ between buyers (population centre of gravity of geographical segments) and sellers (quarries and recycling facilities) in Loire Atlantique

\begin{tabular}{|c|c|c|c|c|c|c|c|c|c|c|}
\hline $\begin{array}{l}\text { geographical } \\
\text { segment }\end{array}$ & Seller & BUYER 1 & BUYER 2 & BUYER 3 & BUYER 4 & BUYER 5 & BUYER 6 & BUYER 7 & BUYER 8 & BUYER 9 \\
\hline 1 & Q1 & 9.07 & 77.27 & 99.29 & 65.45 & 41.08 & 34.1 & 79 & 40.82 & 73.6 \\
\hline 1 & Q2 & 22.23 & 60.32 & 81.8 & 79.65 & 24.2 & 46.09 & 72.06 & 20.04 & 55.69 \\
\hline 1 & Q3 & 22.23 & 60.32 & 81.8 & 79.65 & 24.2 & 46.09 & 72.06 & 20.04 & 55.69 \\
\hline 2 & Q4 & 93.68 & 35.22 & 50.98 & 53.19 & 64.44 & 70.86 & 28.05 & 85.46 & 71.97 \\
\hline 2 & Q5 & 70.28 & 17.07 & 23.15 & 71.64 & 35.82 & 76.95 & 47.98 & 50.84 & 24.67 \\
\hline 2 & Q6 & 57.69 & 24.08 & 37.16 & 65.66 & 23.23 & 64.36 & 45.5 & 39.95 & 27.76 \\
\hline 2 & Q7 & 72.26 & 1.95 & 32.92 & 56.06 & 38.9 & 72.14 & 32.4 & 59.69 & 41.75 \\
\hline 2 & Q8 & 72.26 & 1.95 & 32.92 & 56.06 & 38.9 & 72.14 & 32.4 & 59.69 & 41.75 \\
\hline 2 & Q9 & 57.55 & 26.67 & 37.76 & 74.26 & 25.14 & 65 & 53.96 & 35.98 & 19.36 \\
\hline 3 & Q10 & 87.33 & 37.92 & 23.97 & 95.81 & 54.93 & 94.79 & 72.15 & 61.07 & 24.95 \\
\hline 3 & Q11 & 95.72 & 30.47 & 11.95 & 86.65 & 62.37 & 102.4 & 62.51 & 77.71 & 49.7 \\
\hline 3 & Q12 & 94.07 & 49.53 & 30.53 & 106.94 & 61.56 & 101.43 & 83.56 & 64.96 & 31.05 \\
\hline 3 & Q13 & 83.82 & 28.11 & 16.29 & 86 & 51.41 & 91.28 & 62.34 & 62.26 & 28.02 \\
\hline 3 & Q14 & 106.38 & 44.32 & 13.34 & 100.82 & 72.32 & 113.45 & 77.16 & 84.82 & 53.58 \\
\hline 4 & Q15 & 63.61 & 42.76 & 73.73 & 18.93 & 47.31 & 33.92 & 15.85 & 69.43 & 73.38 \\
\hline 4 & Q16 & 39.56 & 69.86 & 100.83 & 28.89 & 45.07 & 9.88 & 42.44 & 59.8 & 78.74 \\
\hline 4 & Q17 & 79.73 & 55.55 & 84.29 & 20.93 & 65.73 & 50.04 & 21.38 & 88.65 & 87.09 \\
\hline 5 & Q18 & 28.09 & 44.82 & 68.12 & 63.98 & 9.57 & 34.63 & 53.26 & 23.06 & 43.23 \\
\hline
\end{tabular}




\begin{tabular}{|c|c|c|c|c|c|c|c|c|c|c|}
\hline \begin{tabular}{|l|} 
geographical \\
segment
\end{tabular} & Seller & BUYER 1 & BUYER 2 & BUYER 3 & BUYER 4 & BUYER 5 & BUYER 6 & BUYER 7 & BUYER 8 & BUYER 9 \\
\hline 6 & Q19 & 26.93 & 75.19 & 98.64 & 36.61 & 41.36 & 2.74 & 50.16 & 55.71 & 75.04 \\
\hline 6 & Q20 & 25.74 & 67.35 & 90.81 & 47.73 & 33.52 & 13.92 & 61.29 & 48.25 & 67.2 \\
\hline 6 & Q21 & 13.29 & 61.51 & 84.97 & 52.97 & 27.69 & 19.1 & 66.52 & 42.04 & 61.36 \\
\hline 6 & Q22 & 28.21 & 61.98 & 85.44 & 44.36 & 28.15 & 15.01 & 57.91 & 42.88 & 61.83 \\
\hline 7 & Q23 & 69.46 & 25.91 & 56.88 & 38.88 & 40.23 & 54.97 & 10.94 & 63.16 & 57.48 \\
\hline 7 & Q24 & 69.46 & 25.91 & 56.88 & 38.88 & 40.23 & 54.97 & 10.94 & 63.16 & 57.48 \\
\hline 7 & Q25 & 68.13 & 27.64 & 58.61 & 32.3 & 38.9 & 48.39 & 11.32 & 61.83 & 58.27 \\
\hline 7 & Q26 & 68.13 & 27.64 & 58.61 & 32.3 & 38.9 & 48.39 & 11.32 & 61.83 & 58.27 \\
\hline 7 & Q27 & 82.87 & 43.65 & 71.53 & 32.03 & 54.99 & 53.19 & 10.76 & 77.91 & 76.41 \\
\hline 7 & Q28 & 81.77 & 28.28 & 56.16 & 44.28 & 52.54 & 60.27 & 13.64 & 75.41 & 64.68 \\
\hline 8 & Q29 & 39.52 & 51.29 & 66.99 & 79.07 & 16.56 & 51.02 & 66.05 & 6.96 & 36.96 \\
\hline 8 & Q30 & 40.44 & 63.12 & 79.33 & 89.45 & 26.94 & 60.85 & 76.43 & 5.57 & 40.86 \\
\hline 8 & Q31 & 48.62 & 61.52 & 72.95 & 89.67 & 27.16 & 61.62 & 76.66 & 9.74 & 32.62 \\
\hline 9 & Q32 & 72.16 & 33.9 & 33.05 & 84.2 & 39.75 & 79.62 & 63.9 & 48.29 & 12.59 \\
\hline 9 & Q33 & 72.16 & 33.9 & 33.05 & 84.2 & 39.75 & 79.62 & 63.9 & 48.29 & 12.59 \\
\hline 1 & R1 & 9.07 & 77.27 & 99.29 & 65.45 & 41.08 & 34.1 & 79 & 40.82 & 73.6 \\
\hline 1 & R2 & 22.23 & 60.32 & 81.8 & 79.65 & 24.2 & 46.09 & 72.06 & 20.04 & 55.69 \\
\hline 1 & R3 & 22.23 & 60.32 & 81.8 & 79.65 & 24.2 & 46.09 & 72.06 & 20.04 & 55.69 \\
\hline 2 & R4 & 82.27 & 16.39 & 16.72 & 72.57 & 48.92 & 88.66 & 48.91 & 65.01 & 38.79 \\
\hline 2 & R5 & 57.92 & 24.51 & 36.73 & 66.09 & 23.45 & 64.59 & 45.93 & 40.18 & 27.33 \\
\hline 2 & R6 & 57.55 & 26.67 & 37.76 & 74.26 & 25.14 & 65 & 53.96 & 35.98 & 19.36 \\
\hline 3 & R7 & 97.41 & 35.35 & 4.37 & 91.85 & 63.35 & 104.48 & 68.19 & 75.85 & 43.18 \\
\hline 3 & R8 & 91.91 & 35.25 & 9.85 & 93.14 & 59.5 & 99.36 & 69.48 & 70.35 & 36.1 \\
\hline 3 & R9 & 83.2 & 40.27 & 30.84 & 95.59 & 50.71 & 90.57 & 72.04 & 54.75 & 20.67 \\
\hline 3 & R10 & 23.72 & 72.91 & 96.36 & 39.83 & 39.08 & 5.96 & 53.38 & 53.43 & 72.76 \\
\hline 3 & R11 & 94.07 & 49.53 & 30.53 & 106.94 & 61.56 & 101.43 & 83.56 & 64.96 & 31.05 \\
\hline
\end{tabular}




\begin{tabular}{|c|c|c|c|c|c|c|c|c|c|c|}
\hline \begin{tabular}{|l|} 
geographical \\
segment
\end{tabular} & Seller & BUYER 1 & BUYER 2 & BUYER 3 & BUYER 4 & BUYER 5 & BUYER 6 & BUYER 7 & BUYER 8 & BUYER 9 \\
\hline 3 & R12 & 87.33 & 37.92 & 23.97 & 95.81 & 54.93 & 94.79 & 72.15 & 61.07 & 24.95 \\
\hline 3 & R13 & 96.56 & 34.5 & 3.53 & 91 & 62.5 & 103.64 & 67.34 & 75 & 43.44 \\
\hline 4 & R14 & 84.3 & 76.43 & 105.17 & 21.71 & 83.59 & 54.62 & 42.25 & 105.72 & 107.96 \\
\hline 4 & R15 & 54.7 & 49.64 & 80.61 & 10.02 & 55.47 & 25.02 & 22.22 & 76.67 & 80.26 \\
\hline 4 & R16 & 54.7 & 49.64 & 80.61 & 10.02 & 55.47 & 25.02 & 22.22 & 76.67 & 80.26 \\
\hline 4 & R17 & 54.7 & 49.64 & 80.61 & 10.02 & 55.47 & 25.02 & 22.22 & 76.67 & 80.26 \\
\hline 4 & R18 & 54.7 & 49.64 & 80.61 & 10.02 & 55.47 & 25.02 & 22.22 & 76.67 & 80.26 \\
\hline 4 & R19 & 39.56 & 69.86 & 100.83 & 28.89 & 45.07 & 9.88 & 42.44 & 59.8 & 78.74 \\
\hline 4 & R20 & 63.61 & 42.76 & 73.73 & 18.93 & 47.31 & 33.92 & 15.85 & 69.43 & 73.38 \\
\hline 4 & R21 & 79.73 & 55.55 & 84.29 & 20.93 & 65.73 & 50.04 & 21.38 & 88.65 & 87.09 \\
\hline 4 & R22 & 54.7 & 49.64 & 80.61 & 10.02 & 55.47 & 25.02 & 22.22 & 76.67 & 80.26 \\
\hline 4 & R23 & 54.7 & 49.64 & 80.61 & 10.02 & 55.47 & 25.02 & 22.22 & 76.67 & 80.26 \\
\hline 5 & R24 & 36.85 & 35.68 & 57.85 & 64.35 & 1.75 & 43.46 & 50.29 & 23.25 & 35.06 \\
\hline 5 & R25 & 35.1 & 41.26 & 65.26 & 59.25 & 10.71 & 41.77 & 47.4 & 30.22 & 46.17 \\
\hline 5 & R26 & 33.18 & 38.16 & 61.05 & 59.65 & 3.77 & 39.85 & 46.64 & 25.9 & 39.23 \\
\hline 5 & R27 & 39.81 & 41.06 & 65.06 & 54.1 & 14.32 & 46.48 & 42.25 & 34.56 & 49.79 \\
\hline 5 & R28 & 37.22 & 38.87 & 58.85 & 66.91 & 4.31 & 43.83 & 52.85 & 22.51 & 32.81 \\
\hline 5 & R29 & 28.09 & 44.82 & 68.12 & 63.98 & 9.57 & 34.63 & 53.26 & 23.06 & 43.23 \\
\hline 5 & R30 & 37.22 & 38.87 & 58.85 & 66.91 & 4.31 & 43.83 & 52.85 & 22.51 & 32.81 \\
\hline 5 & R31 & 39.81 & 41.06 & 65.06 & 54.1 & 14.32 & 46.48 & 42.25 & 34.56 & 49.79 \\
\hline 5 & R32 & 37.22 & 38.87 & 58.85 & 66.91 & 4.31 & 43.83 & 52.85 & 22.51 & 32.81 \\
\hline 5 & R33 & 36.85 & 35.68 & 57.85 & 64.35 & 1.75 & 43.46 & 50.29 & 23.25 & 35.06 \\
\hline 5 & R34 & 106.87 & 44.81 & 13.84 & 101.31 & 72.81 & 113.95 & 77.65 & 85.31 & 54.08 \\
\hline 5 & R35 & 54.95 & 35.37 & 66.34 & 41.21 & 26.69 & 56.66 & 29.36 & 48.82 & 60.35 \\
\hline 6 & R36 & 20.91 & 69.9 & 93.36 & 42.84 & 36.08 & 8.97 & 56.39 & 50.43 & 69.75 \\
\hline 6 & R37 & 28.21 & 61.98 & 85.44 & 44.36 & 28.15 & 15.01 & 57.91 & 42.88 & 61.83 \\
\hline
\end{tabular}




\begin{tabular}{|c|c|c|c|c|c|c|c|c|c|c|}
\hline \begin{tabular}{|l|} 
geographical \\
segment \\
\end{tabular} & Seller & BUYER 1 & BUYER 2 & BUYER 3 & BUYER 4 & BUYER 5 & BUYER 6 & BUYER 7 & BUYER 8 & BUYER 9 \\
\hline 6 & R38 & 72.16 & 33.9 & 33.05 & 84.2 & 39.75 & 79.62 & 63.9 & 48.29 & 12.59 \\
\hline 6 & R39 & 69.43 & 28.94 & 59.91 & 32.2 & 40.2 & 48.29 & 10.94 & 63.12 & 59.56 \\
\hline 7 & R40 & 58.16 & 28.77 & 59.74 & 37.12 & 28.93 & 53.2 & 23.32 & 51.85 & 57.12 \\
\hline 7 & R41 & 37.22 & 38.87 & 58.85 & 66.91 & 4.31 & 43.83 & 52.85 & 22.51 & 32.81 \\
\hline 7 & R42 & 69.43 & 28.94 & 59.91 & 32.2 & 40.2 & 48.29 & 10.94 & 63.12 & 59.56 \\
\hline 7 & R43 & 69.46 & 25.91 & 56.88 & 38.88 & 40.23 & 54.97 & 10.94 & 63.16 & 57.48 \\
\hline 8 & R44 & 46.37 & 49.72 & 62.75 & 83.65 & 21.41 & 56.79 & 69.58 & 13.83 & 26 \\
\hline 8 & R45 & 57.4 & 59.24 & 63.38 & 94.8 & 32.57 & 67.82 & 80.74 & 18.67 & 23.05 \\
\hline 8 & R46 & 48.62 & 61.52 & 72.95 & 89.67 & 27.16 & 61.62 & 76.66 & 9.74 & 32.62 \\
\hline 8 & R47 & 40.32 & 63.06 & 78.76 & 90.02 & 27.51 & 61.43 & 77.01 & 5 & 40.29 \\
\hline 8 & R48 & 48.62 & 61.52 & 72.95 & 89.67 & 27.16 & 61.62 & 76.66 & 9.74 & 32.62 \\
\hline 8 & R49 & 29.53 & 69.76 & 91.24 & 87.26 & 33.61 & 53.4 & 81.47 & 22.03 & 59.84 \\
\hline 8 & R50 & 37.64 & 53.37 & 69.07 & 79.79 & 17.28 & 51.19 & 66.77 & 6.21 & 37.67 \\
\hline 8 & R51 & 45.62 & 68.49 & 84.09 & 96.27 & 33.76 & 67.26 & 83.26 & 11.98 & 44.04 \\
\hline 9 & R52 & 54.5 & 40.62 & 49.17 & 84.17 & 23.14 & 62.27 & 67.91 & 29.42 & 15.94 \\
\hline 9 & R53 & 81.92 & 53.25 & 45.13 & 102.04 & 50.87 & 90.73 & 81.74 & 48.25 & 17.86 \\
\hline 9 & R54 & 54.5 & 40.62 & 49.17 & 84.17 & 23.14 & 62.27 & 67.91 & 29.42 & 15.94 \\
\hline 9 & R55 & 13.29 & 61.51 & 84.97 & 52.97 & 27.69 & 19.1 & 66.52 & 42.04 & 61.36 \\
\hline
\end{tabular}




\section{DOWNSCALING ALGORITHM}

The algorithm identifies the first chosen provider for a given construction site (buyer), by the minimum transportation distance for the reference scenario.

At the next step, the algorithm tests if enough resource (either RCC or A1) is available.

- If the A1 demand exceeds the A1 resource, all quarries exit the loop

- If the RCC demand exceeds the RCC resource, all recycling facilities exit the loop.

At the next step, the algorithm tests whether the chosen provider can meet the demand of the construction site as follows:

- If the demand of the given buyer (for A1 or RCC) is more than the production of the seller (quarry or recycling facility respectively), the seller sells as much of the product as it can produce (i.e. its remaining production capacity) and cannot sell product (A1 or RCC) anymore to any other buyers ("the facility (seller) exits the loop").

- Otherwise, the buyer buys A1 or RCC from the chosen seller as much as it requires and will not buy A1 or RCC anymore from other sellers ("the buyer exits the loop").

The routine is iterated until the demands of all buyers for BQA (or A1 and RCC considered separately in the reference scenario) are met (all buyers have exited the loop). 
Supporting Information for:

Mousavi, Ventura and Antheaume. Decision-based territorial Life Cycle Assessment for the Management of Cement Concrete Demolition Waste. Waste Management and Research.

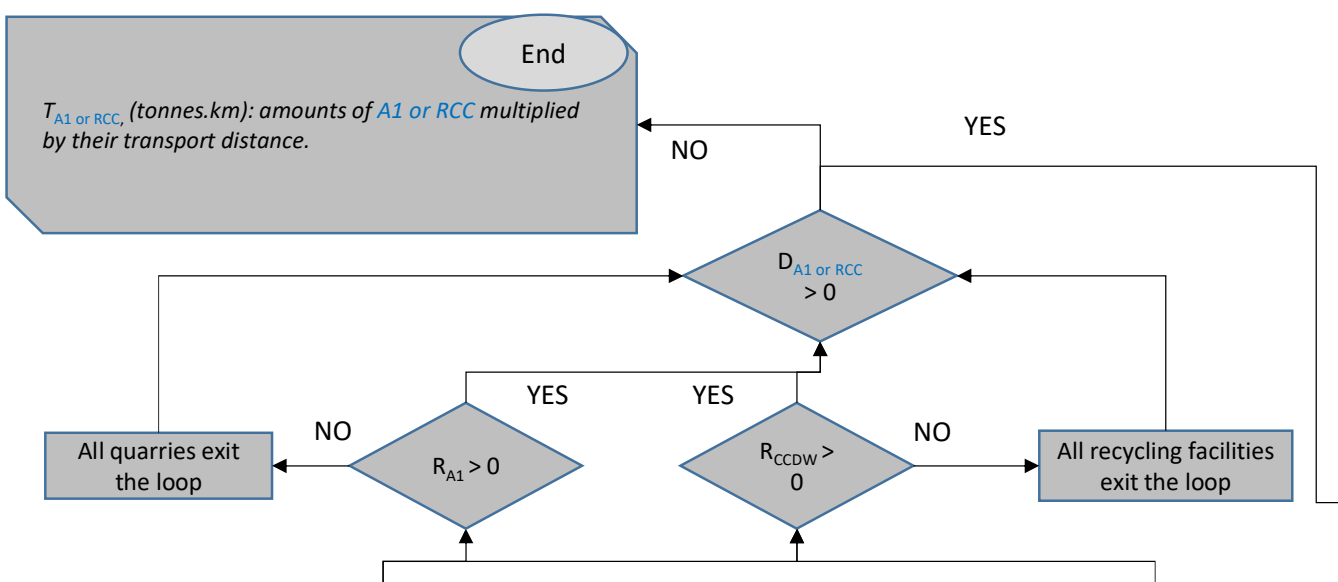

$D_{A 1, m}$ (tonnes): demand of BQA in geographical segment $m$

Demand of buyer of segment $S$ is fulfilled and buyer of segment $S$ exits the loop$$
4
$$

-If facility $F$ is $\operatorname{Prod}_{F}=\operatorname{Prod}_{F}-C \quad D_{A 1 \text { or RCC,S }}=0$

facility $F$ is a recycling platform: $R_{C C W D}=R_{C C O W}-D_{R C C}$ -If facility $F$ is a quarry: $R_{A 1}=R_{A 1}-D_{A}$

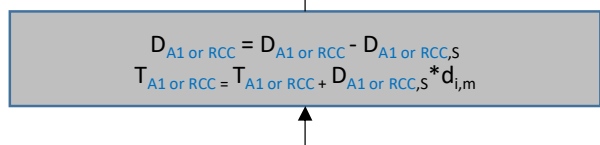

Buyer of segment $S$ buys $D_{A 1}$ or RCC, from facility $F$

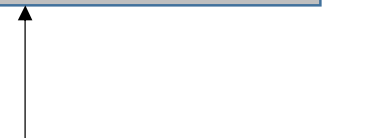

Facility $F$ is empty and exits the loop

-If facility $F$ is a recycling platform: $R_{C C W D}=R_{C C D W}-$ Prod $_{F}$

-If facility F is a recycling platform: $R_{C C W D}$

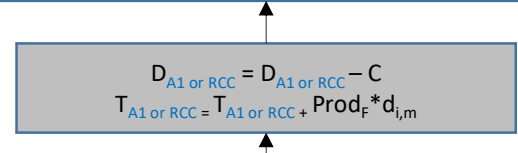

Buyer of segment $S$ buys Prod $_{F}$ from Facility $F$

YES

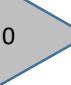

Downscaling

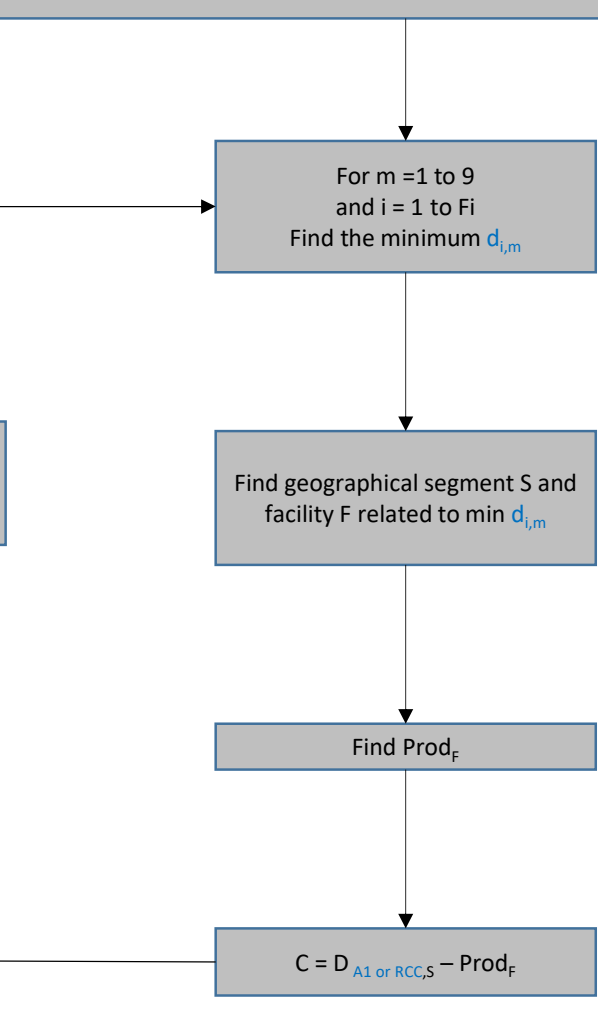

$D_{R C C, m}$ (tonnes): demand of $B Q A$ in geographical segment $m$

$d_{i, m}(\mathrm{~km})$. distance between provideri and buyerm

Prod $_{i}$ (tonnes): production capacity of facility

$F_{i}$ : number of facilities

$T_{B Q A}$ (tonnes. $k m$ ): amounts of $B Q A$ multiplied by their transport distance. $T_{B O A}=0$ at the

start of algorithm.

$R_{A 1}$ (tonnes): total resource of $A 1$, equal to $P_{A 1}$ at the start of algorithm

$R_{\text {CCDW }}$ (tonnes): total resource of CCDW, equal to $P_{\text {CCDW }}$ at the start of algorithm

Start

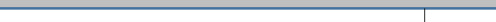




\section{DETAILS OF DATA FOR LOIRE ATLANTIQUE CASE STUDY}

\subsection{Quarries in Loire Atlantique}

Table S 6. List of quarries in Loire-Atlantique (brgm, 2016)

\begin{tabular}{|r|r|r|r|r|}
\hline Quarry's number & $\begin{array}{c}\text { Geographical } \\
\text { segment }\end{array}$ & $\begin{array}{r}\text { Authorized } \\
\text { Production } \\
\text { (tonne) }\end{array}$ & \multicolumn{1}{c|}{$\begin{array}{c}\text { Estimated } \\
\text { production } \\
\text { (tonne) }\end{array}$} & $\begin{array}{c}\text { Estimated A1 } \\
\text { production } \\
\text { (tonne) }\end{array}$ \\
\hline Q1 & 1 & 50,000 & 50,000 & 18,850 \\
\hline Q2 & 1 & 350,000 & 159,451 & 60,113 \\
\hline Q3 & 1 & 550,000 & 279,551 & 105,391 \\
\hline Q4 & 2 & 40,000 & 40,000 & 15,080 \\
\hline Q5 & 2 & 150,000 & 39,351 & 14,835 \\
\hline Q6 & 2 & 600,000 & 309,576 & 116,710 \\
\hline Q7 & 2 & 150,000 & 39,351 & 14,835 \\
\hline Q8 & 2 & 42,000 & 42,000 & 15,834 \\
\hline Q9 & 2 & $1,000,000$ & 549,776 & 207,266 \\
\hline Q10 & 3 & 550,000 & 99,401 & 37,474 \\
\hline Q11 & 3 & 350,000 & 159,451 & 60,113 \\
\hline Q12 & 3 & $1,200,000$ & 669,876 & 252,543 \\
\hline Q13 & 3 & 120,000 & 21,336 & 8,044 \\
\hline Q14 & 3 & 150,000 & 39,351 & 14,835 \\
\hline Q15 & 4 & $1,000,000$ & 600,000 & 226,200 \\
\hline Q16 & 4 & 450,000 & 219,501 & 82,752 \\
\hline Q17 & 4 & $2,500,000$ & $1,400,000$ & 527,800 \\
\hline Q18 & 5 & $1,000,000$ & 549,776 & 207,266 \\
\hline Q19 & 6 & $1,000,000$ & 549,776 & 207,266 \\
\hline Q20 & 6 & 600,000 & 309,576 & 116,710 \\
\hline Q21 & 6 & 300,000 & 129,426 & 48,794 \\
\hline Q22 & 6 & 830,000 & 447,691 & 168,780 \\
\hline Q23 & 7 & 300,000 & 100,000 & 37,700 \\
\hline Q24 & 7 & 160,000 & 45,356 & 17,099 \\
\hline Q25 & 7 & 600,000 & 309,576 & 116,710 \\
\hline Q26 & 7 & 400,000 & 189,476 & 71,433 \\
\hline Q27 & 7 & 300,000 & 129,426 & 48,794 \\
\hline Q29 & 7 & 600,000 & 309,576 & 116,710 \\
\hline Q30 & 8 & 600,000 & 550,000 & 207,350 \\
\hline & 8 & 830,000 & 447,691 & 168,780 \\
\hline & & 600,000 & 309,576 & 116,710 \\
\hline & 250,000 & 99,401 & 37,474 \\
\hline & & & & 26,155 \\
\hline
\end{tabular}


Supporting Information for:

Mousavi, Ventura and Antheaume. Decision-based territorial Life Cycle Assessment for the Management of Cement Concrete Demolition Waste. Waste Management and Research

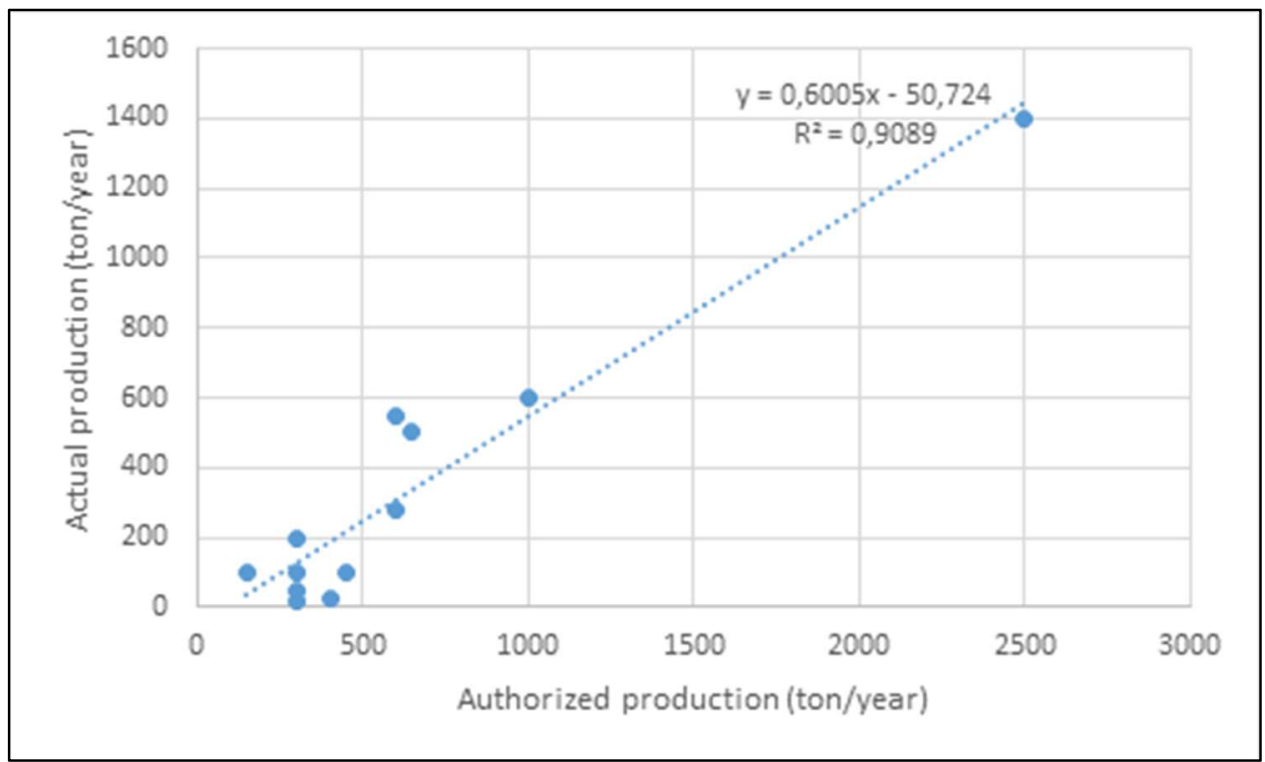

Fig. S 2. Actual production versus authorized production in the quarries of Charier Company

Table S 7. Production and mass ratios of the products in Charier Company's quarries located in Pays de la Loire, France

\begin{tabular}{|l|r|r|}
\hline Products in the quarries & $\begin{array}{c}\text { Production in Charier Company's quarries } \\
\text { (tonne) }\end{array}$ & Mass ratio (\%) \\
\hline A1 & $1,408,000$ & $\beta 1=37.7$ \\
\hline A2 & 698,000 & $\beta 2=18.7$ \\
\hline A3 & $1,632,000$ & $\beta 3=43.6$ \\
\hline Total & $3,738,000$ & 100 \\
\hline
\end{tabular}

Table S 8. Demand for the products and related mass ratios in Charier Company's quarries

\begin{tabular}{|l|r|r|r|}
\hline Products in the quarries & $\begin{array}{c}\text { Demands from Charier } \\
\text { Company's quarries } \\
\text { (tonne) }\end{array}$ & $\begin{array}{c}\text { Demand mass } \\
\text { ratios to A3 (\%) }\end{array}$ & $\begin{array}{c}\text { Demand in Loire } \\
\text { Atlantique in 2012 }\end{array}$ \\
\hline A1 & $1,197,500$ & 75 & $1,605,000$ \\
\hline A2 & 719,000 & 45 & 963,000 \\
\hline A3 & $1,596,000$ & 100 & $2,140,000$ \\
\hline
\end{tabular}

\subsection{Recycling facilities database creation}


Mousavi, Ventura and Antheaume. Decision-based territorial Life Cycle Assessment for the Management of Cement Concrete Demolition Waste. Waste Management and Research.

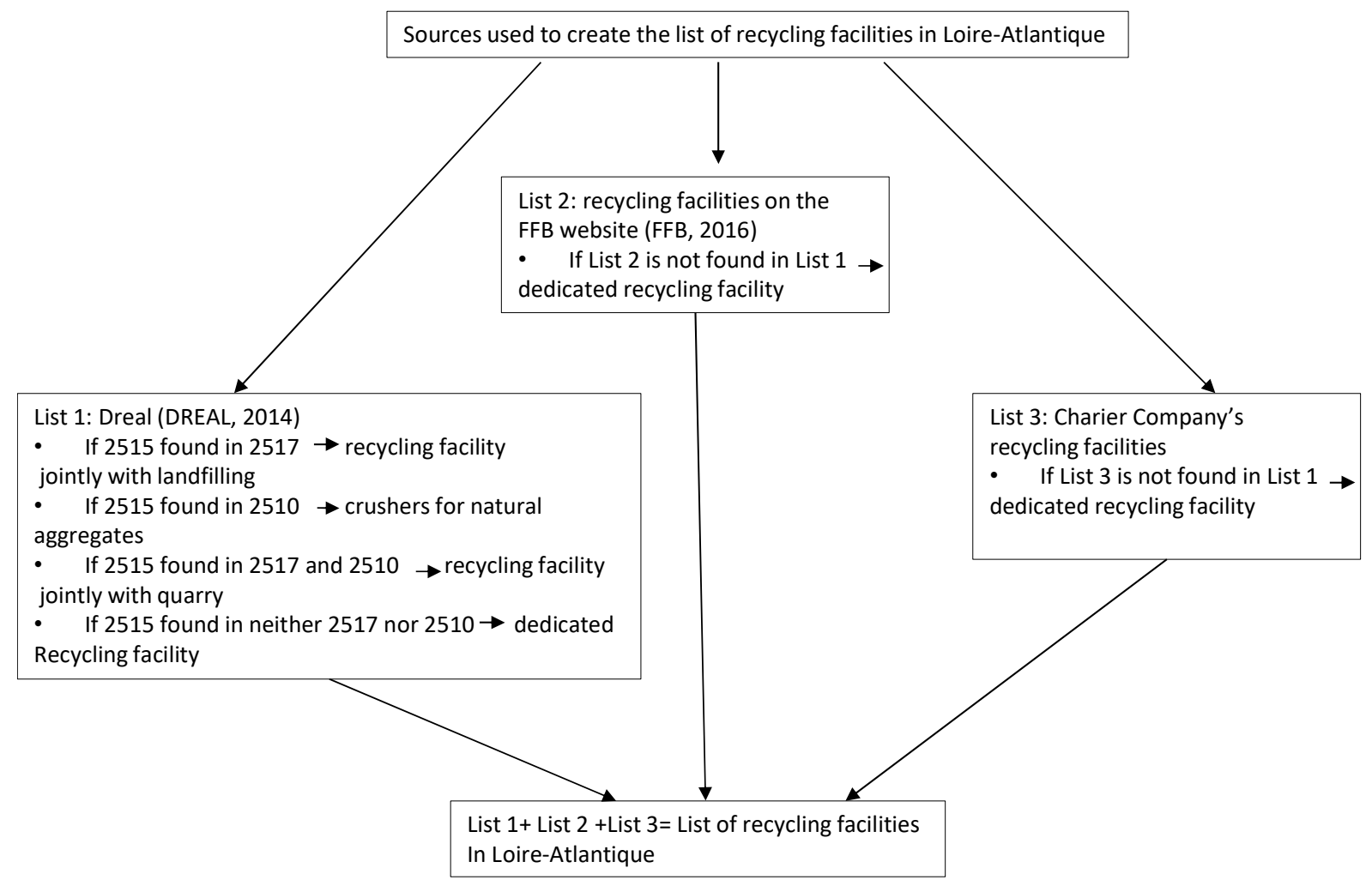

Fig. S 3. Summary of sources used and assumptions made to create the list of recycling facilities in Loire-Atlantique.

A database of all classified activities with their postal addresses was obtained from the French administration for Environment, Planning and Housing website (DREAL, 2019). We extracted data for Loire-Atlantique using the "nomenclature of classified installations" ${ }^{1}$ provides numbers for the following activities:

- $\quad 2510$ : quarry operation (exploitation de carrières)

- 2515 : grinding, crushing, ... and other mineral products or inert non-hazardous waste («Broyage, concassage, ...et autres produits minéraux ou déchets inertes non dangereux »)

- 2517: mineral products with non-hazardous waste inerts (transit) («produits minéraux ou déchets inertes non dangereux (transit)»)

The identification of the recycling facilities was conducted using the following procedure:

\section{1 “nomenclature des installations classées"}


Mousavi, Ventura and Antheaume. Decision-based territorial Life Cycle Assessment for the Management of Cement Concrete Demolition Waste. Waste Management and Research.

- Activities ' 2515 ' that had common addresses with activities ' 2517 ' were assumed to be recycling facilities jointly operating with the landfills. We know according to the facility owners that, some inert landfills can rent mobile crushers that crush demolished wastes to produce recycled products.

- Activities '2515' that had common addresses with activities '2510' were assumed to be crushers for natural aggregates, not for the mineral wastes.

- Activities '2515' that had a common address with both activities '2517' and '2510' were assumed to be recycling facilities jointly operating with the quarries. Indeed, this implies that quarries receive wastes beside quarry operation.

- Activities ' 2515 ' that had no common addresses with both activities ' 2517 ' and ' 2510 ' were assumed to be dedicated recycling facilities.

Finally, the list of recycling facilities obtained was compared with the recycling facilities found on the FFB website (FFB, 2016) and Charier Company's ${ }^{2}$ recycling facilities. Accordingly, some recycling facilities that had not been found on the DREAL website were added to the list of recycling facilities. The final list of recycling facilities in Loire-Atlantique is presented in Erreur ! Source du renvoi introuvable. in Supporting Information.

${ }^{2}$ Charier Company is one of the largest producers of natural aggregates and recycled concrete in the region of Pays de la Loire. 
Supporting Information for:

Mousavi, Ventura and Antheaume. Decision-based territorial Life Cycle Assessment for the Management of Cement Concrete Demolition

Waste. Waste Management and Research.

\subsection{Recycling facilities in Loire Atlantique}

Table S 9. Average production capacities of recycling facilities by geographical segment

\begin{tabular}{|c|c|c|c|c|c|c|c|c|c|c|}
\hline & \multicolumn{10}{|c|}{ Geographical segment } \\
\hline & B1 & B2 & B3 & B4 & B5 & B6 & B7 & B8 & B9 & Total \\
\hline$\%$ population & $5 \%$ & $6 \%$ & $3 \%$ & $15 \%$ & $50 \%$ & $5 \%$ & $6 \%$ & $7 \%$ & $5 \%$ & $100 \%$ \\
\hline RCC demand (tonnes) & 6,124 & 7,728 & 3,946 & 18,818 & 64,186 & 5,879 & 7,513 & 9,242 & 6,164 & 129,600 \\
\hline $\begin{array}{l}\text { number of recycling } \\
\text { facilities }\end{array}$ & 3 & 3 & 7 & 10 & 12 & 4 & 4 & 8 & 4 & 55 \\
\hline $\begin{array}{lr}\begin{array}{l}\text { Production capacity of } \\
\text { recycling }\end{array} \\
\text { (tonnes.year }{ }^{-1} \text { ) }\end{array}$ & 4,083 & 5,152 & 1,127 & 3,764 & 10,698 & 2,940 & 3,756 & 2,310 & 3,082 & $\begin{array}{r}\text { Average: } \\
4,101 \\
\end{array}$ \\
\hline
\end{tabular}

The production capacities of recycling facilities are calculated from Equation 15, in the main article. The value of $r$ should be set so as it should not prevent a buyer from an adjacent segment to buy in that facility. If $r=1$, the facility is set to provide the exact demand to its own segment and is thus empty for demands of adjacent segments. However, a recycling facility close to a border could be closer from a buyer from an adjacent segment. A sensitivity analysis with a multiplication coefficient on the production capacities was carried out with values between of $r$ ranging from 1 to 20 . We observe the effect of this variation on the total transported amounts, to observe the bias. Results are presented in Fig. 6 in main manuscript: they show a decrease in transported amounts with an increase in the production capacities of recycling facilities close to the borders of other geographical segments. This decrease is mainly driven by geographical segments 4 and 5 . It becomes stable between 5 and 10, because the demand for RCC is totally fulfilled by the closest recycling facilities. This means that calculating production capacities separately for each geographical segment can lead to important differences in results due to border effects.

Fig. S 4 below also shows that the number of recycling facilities not selling any product will increase and stabilise to 39, while increasing the value of $r$. This means that favouring fewer recycling facilities with higher production capacities will importantly decrease transports needs. 
Mousavi, Ventura and Antheaume. Decision-based territorial Life Cycle Assessment for the Management of Cement Concrete Demolition Waste. Waste Management and Research.

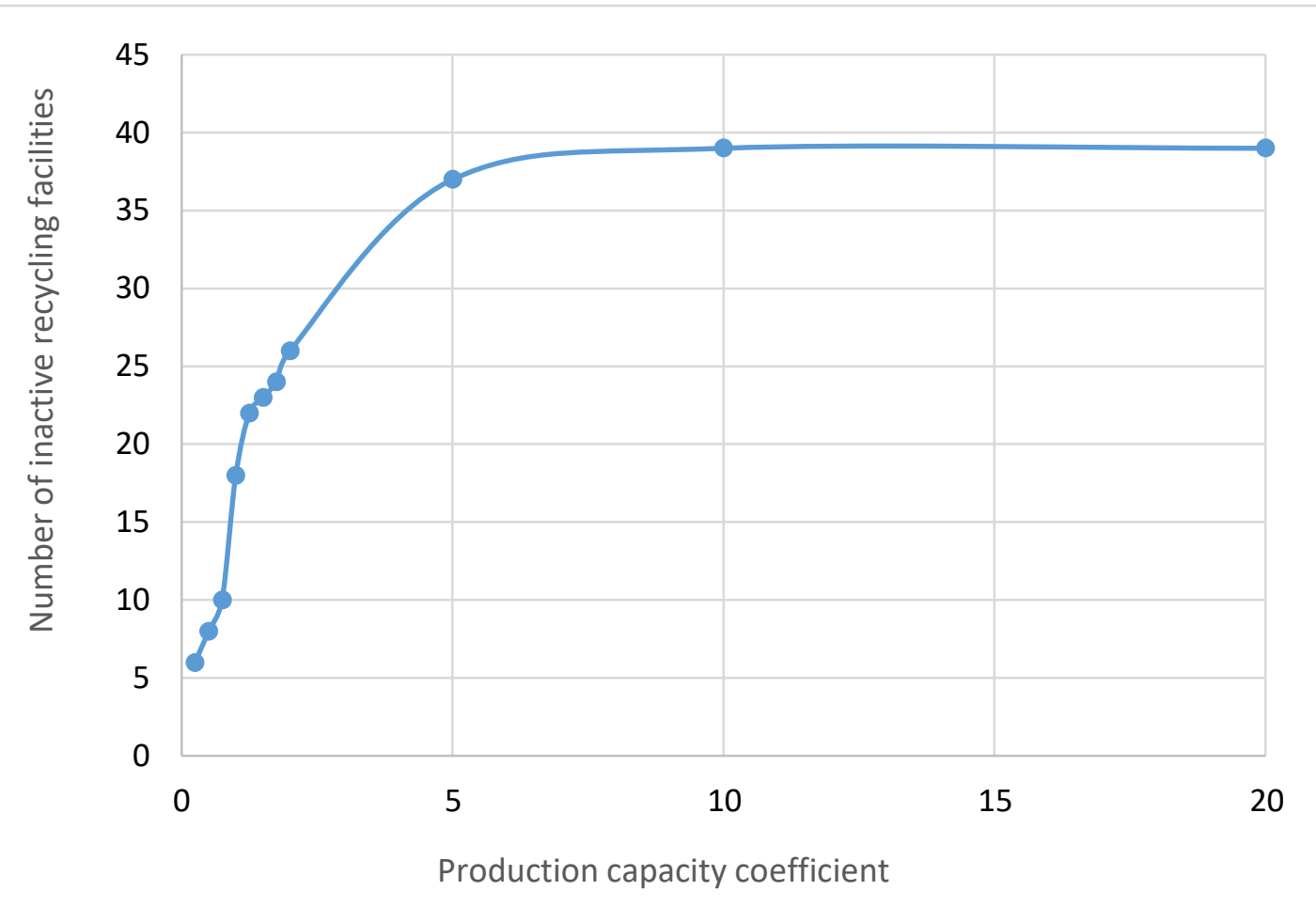

Fig. S 4. Number of recycling facilities not selling any RCC as a function of their production capacities

\subsection{Population in Loire Atlantique}

Table S 10. Populations of the geographical segments in Fig. 4

\begin{tabular}{|l|r|}
\hline Geographical segment & Population of the geographical segment (year 2012) \\
\hline 1 & 62,739 \\
\hline 2 & 79,170 \\
\hline 3 & 40,420 \\
\hline 4 & 192,771 \\
\hline 5 & 657,536 \\
\hline 6 & 60,229 \\
\hline 7 & 76,960 \\
\hline 8 & 94,673 \\
\hline 9 & 63,145 \\
\hline Total & $1,327,643$ \\
\hline
\end{tabular}

\subsection{Main data available from MFA conducted by CERC}

Table S 11. Amounts and composition of inert waste in 2012. Source: (CERC, 2013) p17 
Supporting Information for:

Mousavi, Ventura and Antheaume. Decision-based territorial Life Cycle Assessment for the Management of Cement Concrete Demolition

Waste. Waste Management and Research.

\begin{tabular}{|c|c|c|c|c|}
\hline Nature & $\begin{array}{l}\text { Amount } \\
\text { (tonnes) }\end{array}$ & $\begin{array}{c}\text { \% of hard } \\
\text { materials* } \\
\text { excl. } \\
\text { bricks }\end{array}$ & $\begin{array}{c}\text { \%of } \\
\text { total } \\
\text { C\&DW }\end{array}$ & Assumption about destination \\
\hline Soil and unpolluted loose materials & $1,738,000$ & --- & 72,9 & $\begin{array}{r}\text { Quarry filling, planning projects, inert } \\
\text { landfill }\end{array}$ \\
\hline Gravels and rock materials* & 101,000 & 33.0 & 4,2 & $\begin{array}{l}\text { Recycling, quarry filling, planning } \\
\text { projects, temporary storage, inert landfill }\end{array}$ \\
\hline Reclaimed asphalt pavement (RAP)* & 61,000 & 19.9 & 2,6 & $\begin{array}{r}\text { Asphalt plant, planning project, temporary } \\
\text { storage }\end{array}$ \\
\hline Cement concrete (CCDW)* & 144,000 & 47.0 & 6,0 & $\begin{array}{l}\text { Recycling, quarry filling, planning } \\
\text { projects, temporary storage, inert landfill }\end{array}$ \\
\hline Bricks, tiles, ceramics & 35,000 & --- & 1,5 & $\begin{array}{r}\text { Quarry filling, planning projects, inert } \\
\text { landfill }\end{array}$ \\
\hline Mix of inert waste & 301,000 & --- & 12,6 & $\begin{array}{r}\text { Quarry filling, planning projects, inert } \\
\text { landfill }\end{array}$ \\
\hline $\begin{array}{l}\text { Total hard materials* excl. bricks, tiles } \\
\text { and ceramics }\end{array}$ & 306,000 & 100 & 14,3 & \\
\hline Total inert C\&DW & $2,381,000$ & --- & 100 & \\
\hline
\end{tabular}


Supporting Information for:

Mousavi, Ventura and Antheaume. Decision-based territorial Life Cycle Assessment for the Management of Cement Concrete Demolition

Waste. Waste Management and Research.

Table S 12. Destination of waste types in 2012. Source: (CERC, 2013) p17

\begin{tabular}{|l|r|r|r|r|}
\hline \multicolumn{1}{|c|}{ Destination } & \multicolumn{1}{c|}{$\begin{array}{c}\text { total } \\
\text { (ktonnes) }\end{array}$} & $\begin{array}{c}\text { inert } \\
\text { (ktonnes) }\end{array}$ & $\begin{array}{c}\text { non } \\
\text { dangerous } \\
\text { (ktonnes) }\end{array}$ & $\begin{array}{c}\text { Dangerous } \\
\text { (ktonnes) }\end{array}$ \\
\hline reference in CERC report & \multicolumn{1}{|c|}{ page 14} & \multicolumn{1}{c|}{ page 18 } & page 21 & page 23 \\
\hline Quarry filling & $1,261.0$ & $1,261.0$ & & \\
\hline Recycling and material recov. inside Loire Atlantique & 283.0 & 244.0 & 38.0 & \\
\hline Recycling and material recov. outside Loire Atlantique & 6.0 & & 6.0 & \\
\hline Asphalt plant & 54.0 & 54.0 & & \\
\hline Use in urban planning & 46.0 & 46.0 & & \\
\hline Energy recovery inside Loire Atlantique & 2.0 & & 2.0 & \\
\hline Energy recovery outside Loire Atlantique & 0.6 & & 0.6 & \\
\hline Elimination in landfill inside Loire Atlantique & 719.0 & 719.0 & & \\
\hline Elimination in landfill outside Loire Atlantique & 19.0 & & 16.0 & \\
\hline Temporary storage & 57.0 & 57.0 & & \\
\hline Unknown destination & 11.0 & & 7.0 & \\
\hline Incineration & 0.5 & & & \\
\hline TOTAL & $2,459.1$ & $2,381.0$ & 70.1 & \\
\hline
\end{tabular}


Supporting Information for:

Mousavi, Ventura and Antheaume. Decision-based territorial Life Cycle Assessment for the Management of Cement Concrete Demolition

Waste. Waste Management and Research.

Table S 13. Percentages to destination by types of inert waste in 2012. Source: (CERC, 2013) p19-np: not provided

\begin{tabular}{|c|c|c|c|c|c|c|}
\hline & mix & concrete & gravels & asphalt & $\begin{array}{l}\text { exc. } \\
\text { soil }\end{array}$ & $\begin{array}{l}\text { bricks, } \\
\text { tiles... }\end{array}$ \\
\hline Quarry filling & $15 \%$ & $5 \%$ & $3 \%$ & & $68 \%$ & $\mathrm{np}$ \\
\hline $\begin{array}{l}\text { Recycling and material recov. inside Loire } \\
\text { Atlantique }\end{array}$ & $7 \%$ & $90 \%$ & $71 \%$ & $16 \%$ & $1 \%$ & $\mathrm{np}$ \\
\hline $\begin{array}{l}\text { Recycling and material recov. outside Loire } \\
\text { Atlantique }\end{array}$ & & & & & & $\mathrm{np}$ \\
\hline Asphalt plant & & & & $82 \%$ & & np \\
\hline Use in urban planning & & & $18 \%$ & & $2 \%$ & np \\
\hline Energy recovery inside Loire Atlantique & & & & & & $\mathrm{np}$ \\
\hline Energy recovery outside Loire Atlantique & & & & & & np \\
\hline Elimination in landfill inside Loire Atlantique & $77 \%$ & & $2 \%$ & $1 \%$ & $28 \%$ & np \\
\hline Elimination in landfill outside Loire Atlantique & & & & & & $\mathrm{np}$ \\
\hline Temporary storage & $1 \%$ & $5 \%$ & $6 \%$ & $1 \%$ & $1 \%$ & $\mathrm{np}$ \\
\hline Unknown destination & & & & & & np \\
\hline Incineration & & & & & & np \\
\hline TOTAL & $100 \%$ & $100 \%$ & $100 \%$ & $100 \%$ & $100 \%$ & \\
\hline
\end{tabular}


Supporting Information for:

Mousavi, Ventura and Antheaume. Decision-based territorial Life Cycle Assessment for the Management of Cement Concrete Demolition

Waste. Waste Management and Research.

Table S 14. Amounts to destination by types of inert waste in 2012. Calculated from (CERC, 2013) p19-np: not provided*total is to be compared with data provided in Table $S 12$

\begin{tabular}{|l|r|r|r|r|r|r|r|}
\hline & mix & \multicolumn{1}{|c|}{ concrete } & \multicolumn{1}{c|}{ gravels } & \multicolumn{1}{c|}{ asphalt } & exc. soil & \multicolumn{1}{|c|}{$\begin{array}{l}\text { bricks, } \\
\text { tiles... }\end{array}$} & TOTAL* \\
\hline Quarry filling & 45.2 & 7.2 & 3.0 & 0.0 & $1,181.8$ & $\mathrm{np}$ & $1,237.2$ \\
\hline $\begin{array}{l}\text { Recycling and material } \\
\text { recovery inside Loire } \\
\text { Atlantique }\end{array}$ & 21.1 & 129.6 & 71.7 & 9.8 & 17.4 & $\mathrm{np}$ & 249.5 \\
\hline $\begin{array}{l}\text { Recycling and material } \\
\text { recovery outside Loire } \\
\text { Atlantique }\end{array}$ & 0.0 & 0.0 & 0.0 & 0.0 & 0.0 & $\mathrm{np}$ & 0.0 \\
\hline Asphalt plant & 0.0 & 0.0 & 0.0 & 50.0 & 0.0 & $\mathrm{np}$ & 50.0 \\
\hline $\begin{array}{l}\text { Use in urban planning } \\
\text { Energy recovery inside } \\
\text { Loire Atlantique }\end{array}$ & 0.0 & 0.0 & 18.2 & 0.0 & 34.8 & $\mathrm{np}$ & 52.9 \\
\hline $\begin{array}{l}\text { Energy recovery outside } \\
\text { Loire Atlantique }\end{array}$ & 0.0 & 0.0 & 0.0 & 0.0 & 0.0 & $\mathrm{np}$ & 0.0 \\
\hline $\begin{array}{l}\text { Elimination in landfill } \\
\text { inside Loire Atlantique }\end{array}$ & 231.8 & 0.0 & 0.0 & 0.0 & 0.0 & $\mathrm{np}$ & 0.0 \\
\hline $\begin{array}{l}\text { Elimination in landfill } \\
\text { outside Loire Atlantique }\end{array}$ & 0.0 & 0.0 & 0.0 & 0.0 & 0.0 & $\mathrm{np}$ & 0.0 \\
\hline Temporary storage & 3.0 & 7.2 & 6.1 & 0.6 & 17.4 & $\mathrm{np}$ & 34.3 \\
\hline Unknown destination & 0.0 & 0.0 & 0.0 & 0.0 & 0.0 & $\mathrm{np}$ & 0.0 \\
\hline Incineration & 0.0 & 0.0 & 0.0 & 0.0 & 0.0 & $\mathrm{np}$ & 0.0 \\
\hline TOTAL & 301.0 & 144.0 & 101.0 & 61.0 & $1,738.0$ & & $2,380.0$ \\
\hline
\end{tabular}

Table S 15 Production and consumptions of materials in Loire-Atlantique (year 2012)

\begin{tabular}{|l|r|c|}
\hline \multicolumn{1}{|c|}{ Parameters of the model } & \multicolumn{1}{c|}{ Amount } & \multicolumn{1}{c|}{ Unit } \\
\hline $\mathrm{D}_{\mathrm{CC}}$ & $1,100,000$ & $\mathrm{~m}^{3}$ \\
\hline $\mathrm{D}_{\mathrm{A} 3 \mathrm{CC}}$ & $1,327,700$ & tonnes \\
\hline $\mathrm{D}_{\mathrm{BC}}$ & 855,000 & tonnes \\
\hline $\mathrm{D}_{\mathrm{A} 3 \mathrm{BC}}$ & 812,250 & tonnes \\
\hline $\mathrm{P}_{\mathrm{A} 3}=\mathrm{D}_{\mathrm{A} 3}$ & $2,140,000$ & tonnes \\
\hline $\mathrm{P}_{\mathrm{A} 1}$ & $1,850,400$ & tonnes \\
\hline $\mathrm{P}_{\mathrm{A} 2}$ & 917,800 & tonnes \\
\hline $\mathrm{D}_{\mathrm{A} 1}$ & $1,676,700$ & tonnes \\
\hline${ }^{\mathrm{a}} \mathrm{D}_{\mathrm{A} 2}$ & 963,000 & tonnes \\
\hline $\mathrm{D}_{\mathrm{RCC}}$ & 129,600 & tonnes \\
\hline${ }^{\mathrm{b}} \mathrm{D}_{\mathrm{BQA}}$ & $1,806,300$ & tonnes \\
\hline
\end{tabular}

a Demand of $A 2$ is calculated from data extrapolated from Charier Company (see Table $S$ 8). It is found slightly superior to the production of A2 calculated from quarry mass ratios, but the two results are close enough to consider there is no stock of A2.

b is the summation of DA1 and 
Supporting Information for:

Mousavi, Ventura and Antheaume. Decision-based territorial Life Cycle Assessment for the Management of Cement Concrete Demolition

Waste. Waste Management and Research.

Table S 16. Amounts (ktonnes) and destination of CCDW and gravels in Loire Atlantique in 2012 (extracted from (CERC, 2013))

\begin{tabular}{|l|r|}
\hline \multicolumn{1}{|c|}{ Destinations } & CCDW ktonnes (\%) \\
\hline Recycling platform & $129.6(90)$ \\
\hline Quarry filling & $7.2(5)$ \\
\hline Temporary storage & $7.2(5)$ \\
\hline Planning projects & \\
\hline Inert landfill & $\mathbf{1 4 4}$ \\
\hline TOTAL & \\
\hline
\end{tabular}

